\title{
Nano-scale chemical evolution in a proton-and neutron- irradiated Zr alloy
}

DOI:

10.1016/j.jnucmat.2017.01.049

\section{Document Version}

Accepted author manuscript

Link to publication record in Manchester Research Explorer

\section{Citation for published version (APA):}

Harte, A., Topping, M., Frankel, P., Jädernäs, D., Romero, J., Hallstadius, L., Darby, E. C., \& Preuss, M. (2017). Nano-scale chemical evolution in a proton-and neutron-irradiated $\mathrm{Zr}$ alloy. Journal of Nuclear Materials, 487, 30-42. https://doi.org/10.1016/j.jnucmat.2017.01.049

\section{Published in:}

Journal of Nuclear Materials

\section{Citing this paper}

Please note that where the full-text provided on Manchester Research Explorer is the Author Accepted Manuscript or Proof version this may differ from the final Published version. If citing, it is advised that you check and use the publisher's definitive version.

\section{General rights}

Copyright and moral rights for the publications made accessible in the Research Explorer are retained by the authors and/or other copyright owners and it is a condition of accessing publications that users recognise and abide by the legal requirements associated with these rights.

\section{Takedown policy}

If you believe that this document breaches copyright please refer to the University of Manchester's Takedown Procedures [http://man.ac.uk/04Y6Bo] or contact uml.scholarlycommunications@manchester.ac.uk providing relevant details, so we can investigate your claim.

\section{OPEN ACCESS}




\title{
Nano-scale chemical evolution in a proton- and neutron-irradiated Zr alloy
}

\author{
Accepted Journal of Nuclear Materials, January 2017 \\ ${ }^{1}$ The University of Manchester, Oxford Road, Manchester, M13 9PL, United Kingdom \\ ${ }^{2}$ Studsvik Nuclear AB, SE 61182 Nyköping, Sweden \\ ${ }^{3}$ Westinghouse Electric Company, Columbia, SC, United States \\ ${ }^{4}$ Westinghouse Electric Sweden AB, SE---72163 Västerås, Sweden \\ ${ }^{5}$ Rolls Royce Plc., Nuclear Materials, Derby, UK
}

A. Harte ${ }^{1}$, M. Topping ${ }^{1}$, P. Frankel ${ }^{1}$, D. Jädernäs ${ }^{2}$, J. Romero $^{3}$, L. Hallstadius ${ }^{4}$, E. C. Darby ${ }^{5}$, M.Preuss ${ }^{1}$.

Contact: Allan Harte, allan.harte@manchester.ac.uk

\begin{abstract}
Proton- and neutron-irradiated Zircaloy-2 are compared in terms of the nano-scale chemical evolution within second phase particles (SPPs) $\mathrm{Zr}(\mathrm{Fe}, \mathrm{Cr})_{2}$ and $\mathrm{Zr}_{2}(\mathrm{Fe}, \mathrm{Ni})$. This is accomplished through ultra-high spatial resolution scanning transmission electron microscopy and the use of energy-dispersive X-ray spectroscopic methods. Fe-depletion is observed from both SPP types after irradiation with both irradiative species, but is heterogeneous in the case of $\mathrm{Zr}(\mathrm{Fe}, \mathrm{Cr})_{2}$, predominantly from the edge region, and homogeneously in the case of $\mathrm{Zr}_{2}(\mathrm{Fe}, \mathrm{Ni})$. Further, there is evidence of a delay in the dissolution of the $\mathrm{Zr}_{2}(\mathrm{Fe}, \mathrm{Ni})$ SPP with respect to the $\mathrm{Zr}(\mathrm{Fe}, \mathrm{Cr})_{2}$. As such, SPP dissolution results in matrix supersaturation with solute under both irradiative species and proton irradiation is considered well suited to emulate the effects of neutron irradiation in this context. The mechanisms of solute redistribution processes from SPPs and the consequences for irradiation-induced growth phenomena are discussed.
\end{abstract}

\section{Introduction}

The use of $\mathrm{Zr}$ alloys as the structural components of nuclear reactor cores is widespread due to their low average neutron absorption cross section and their retention of mechanical properties and corrosion resistance at operating temperatures [1]. Due to their limited solubility in hcp $\alpha-Z r$ [2-4], the common alloying elements Fe, $\mathrm{Cr}$ and $\mathrm{Ni}$ precipitate as thermodynamically stable second phase particles (SPPs) in both the matrix and at grain boundaries [5-8]. In Zircaloy-2, the major intermetallic secondary phases are $\mathrm{Zr}(\mathrm{Fe}, \mathrm{Cr})_{2}$ and $\mathrm{Zr}_{2}(\mathrm{Fe}, \mathrm{Ni})$ with size ranges $20-170$ $\mathrm{nm}$ for Fe-Cr SPPs and 30-650 $\mathrm{nm}$ for Fe-Ni SPPs [9]. While $\mathrm{Zr}-\mathrm{Fe}$ binary SPP intermetallics are sometimes observed in Zircaloy-4 when the alloy composition is $\mathrm{Fe} / \mathrm{Cr}>4$ [3] and zirconium silicides, phosphides and zirconium copper sulphides have been observed in Zircaloy-2 [6,10], their number densities are extremely low by comparison to the $\mathrm{Zr}(\mathrm{Fe}, \mathrm{Cr})_{2}$ and $\mathrm{Zr}_{2}(\mathrm{Fe}, \mathrm{Ni})$ SPPs and so will not be considered explicitly here. As the stoichiometry of the SPPs is variable after irradiation, the $\mathrm{Zr}(\mathrm{Fe}, \mathrm{Cr})_{2}$ and $\mathrm{Zr}_{2}(\mathrm{Fe}, \mathrm{Ni})$ SPPs will hereafter be referred to as $\mathrm{Fe}-\mathrm{Cr}$ type and $\mathrm{Fe}$ Ni type, respectively. The type and morphology of SPPs have been shown to be the principal factor affecting in-reactor corrosion of the Zircaloys [11]. Better corrosion resistance, and hence reduced hydrogen ingress, has recently been shown to correlate with decreased irradiation-induced growth strain [12], a macroscopic deformation process that is characterised in tube by axial expansion and radial contraction. It is generally accepted that growth strain is a result of an excess of interstitials in prismatic planes and vacancies in basal planes as a result of the diffusional anisotropy of irradiation-induced point defects in hcp systems [13-17]. The evolution of intermetallic phases under irradiation is of importance to the system as a whole, as mechanical behaviour and corrosion properties are intrinsically dependent on microstructural features. 
A comparison of pre-breakaway irradiation-induced growth strain at a given fluence in the binary system $\mathrm{Zr}-1.5 \mathrm{Sn}$ (wt.\%) at $280{ }^{\circ} \mathrm{C}$ [18] as compared with that of Zircaloy-2 at $\sim 290{ }^{\circ} \mathrm{C}$ [19] shows that the latter, in which the dominant microstructural difference is the presence of SPPs and impurities, demonstrates a reduced growth strain in comparison to the $\mathrm{Zr}$ $1.5 \mathrm{Sn}$ (wt.\%) alloy. As such, the behaviour of impurities [23] and secondary phases under irradiation in different alloy systems is of interest, as are controlled studies that make use of electron, proton and heavy ion irradiation to better understand the mechanisms of SPP evolution. The effect of chemistry on microstructural features that are correlated to accelerated irradiation-induced growth strain may then be studied systematically, such as the density of c-component dislocations [19] or c-loops [20]. For instance, a higher c-loop density (Burgers vector $\frac{1}{6}\langle 20 \overline{2} 3\rangle$, aligned parallel to the trace of the basal plane $[21,22])$ has been observed in the vicinity of partially dissolved FeCr SPPs in neutron-irradiated Zircaloy-4 in the temperature range $\sim 290-310{ }^{\circ} \mathrm{C}$ and protonirradiated Zircaloy-4 at $350{ }^{\circ} \mathrm{C}$ [23-25]. As such, $\mathrm{Fe}$ is generally thought to have the effect of stabilising the nucleation of the vacancy c-loops, likely through an elastic interstitial (Fe)-vacancy interaction or through stable, crystallographic Fevacancy pairing [25]. There remains an inconsistency that higher growth strains are correlated to higher c-loop densities, higher c-loop densities correlated to regions of high Fe content, and that alloys of greater SPP and impurity content correlated to reduced growth strain at lower irradiation dose in the pre-breakaway regime.

The aim of the present work is to assess the nano-scale chemical evolution in Zircaloy-2 after proton irradiation at lower doses and after and neutron irradiation at higher doses by taking advantage of new developments in STEM-EDS. Further, correlations and differences are highlighted between the effects of the different irradiative species in regards to the irradiationinduced changes within SPPs and the gradual supersaturation of the matrix with solute.

\section{Experimental}

\section{$2.1 \quad$ Material}

The material under investigation is Zircaloy-2, nominally $\mathrm{Zr}-1.5 \mathrm{Sn}-1.4 \mathrm{Fe}-0.1 \mathrm{Cr}-$ $0.06 \mathrm{Ni}$ (wt.\%) [1], supplied by Westinghouse Electric Company. The non-irradiated material was fully recrystallised plate with equiaxed grains of $\sim 5-15 \mu \mathrm{m}$ diameter and a strong basal texture in the normal direction, split $\pm 30^{\circ}$ in the transverse direction. The plate was cut into bars of dimensions $2 \times 2 \times 20 \mathrm{~mm}$ and mechanically polished perpendicular to the normal direction such that the flat surface provides a uniform proton penetration depth. The polished surface of the bars were then proton-irradiated at the Michigan Ion Beam Laboratory's $1.7 \mathrm{MeV}$ Tandertron accelerator facility at $2 \mathrm{MeV}$ and 350 $\pm 9{ }^{\circ} \mathrm{C}$ to doses of $2.3,4.7$ and 7.0 displacements per atom (dpa) at a current of $\sim 0.2 \mu \mathrm{A} \mathrm{mm} \mathrm{mm}^{-2}$, resulting in a damage rate $\sim 6.7 \times 10^{-6} \mathrm{dpa} \mathrm{s}^{-1}$. The proton irradiation dose (dpa) level was calculated at $60 \%$ of the maximum proton penetration depth, $30 \mu \mathrm{m}$, calculated by the quick Kinchin-Pease calculation in SRIM as recommended by Stoller et al. [26]. As such, TEM foils were prepared for examination at this depth by carefully grinding from the non-irradiated face to a thickness of $\sim 160$ $\mu \mathrm{m}$ and then electropolishing using a twin-jet Tenupol-5 electropolisher together with a Julabo FP50 cooling unit. An electrolyte of $10 \%$ perchloric acid and 20\% 2-butoxyethanol in ethanol [24] was used to electropolish $\sim 12-15 \mu \mathrm{m}$ from the irradiated face. Then, acid-resistant varnish was used to protect the irradiated face while electropolishing to perforation from the non-irradiated face. The non-irradiated bulk material was prepared by the same method.

The neutron-irradiated material was supplied by Westinghouse and Studsvik in the form of electropolished TEM foils, which were previously studied to investigate SPP chemical evolution [12]. They are studied in the present work for a direct comparison to the protonirradiated material. These samples were prepared from cladding and channel material of a BWR (280-330 ${ }^{\circ} \mathrm{C}$ [27]), irradiated to neutron fluences between 8.7 and $14.7 \times 10^{25} \mathrm{n} \mathrm{m}^{-2}(\mathrm{E}>1 \mathrm{MeV})$ $\sim 14.5$ to $24.5 \mathrm{dpa}$, assuming a conversion of 0.6 $\mathrm{x} 10^{25} \mathrm{n} \mathrm{m}^{-2} \mathrm{dpa}^{-1}$ [28]. As the damage rate in light water reactors is $\sim 6-1 \times 10^{17} \mathrm{n} \mathrm{m}^{-2} \mathrm{~s}^{-1}$ [28-30], the BWR damage rate is $\sim 1 \times 10^{-7} \mathrm{dpa} \mathrm{s}^{-1}$. As such, the 
proton irradiations in the present work incurred a damage rate higher than that of the neutronirradiated material by a factor of $\sim 70$. To allow more diffusion to occur under such a high damage rate, a temperature shift [31] of $40{ }^{\circ} \mathrm{C}$ was applied to the proton irradiation experiment, which was performed at $350{ }^{\circ} \mathrm{C}$ as opposed to the average $310^{\circ} \mathrm{C}$ in a BWR.

\subsection{Microscopic analysis}

All microscopy in the present work was performed on a G2 80-200 kV spherical aberration-corrected (single, probe) FEI Titan microscope operating at $200 \mathrm{kV}$ in scanning mode with a current of $0.6 \mathrm{nA}$. The microscope is equipped with a high brightness $\mathrm{X}$-FEG electron gun and the FEI ChemiSTEMTM system, comprising four energy-dispersive X-ray (EDS) detectors in close proximity to the sample, resulting in a maximum collection angle of 0.7 srad. While the sample was loaded in a lowbackground double-tilt holder, the determination of chemistry may be considered to be semiquantitative as the Cliff-Lorimer approach was used with calculated $k$-factors, assuming no absorption and not accounting for Fe-scattering from the pole piece. All chemical data was obtained by spectral imaging (a full spectrum up to $20 \mathrm{keV}$ at every pixel), after which chemical maps were extracted for the relevant alloying elements.

Second phase particles (SPPs) were analysed for their chemical content at magnifications high enough to produce a brightfield STEM image in which the SPP constituted $\sim 75 \%$ of the image (between $320 \mathrm{k} \mathrm{x}$ and $640 \mathrm{k} \mathrm{x}$ ). The semi-quantification of SPP chemistry was consistently obtained from low symmetry orientations to avoid electron-channelling phenomena, and data were analysed within the FEI ESPRIT software. While it has been previously shown that it is necessary to subtract a blank background due to emitting $95 \mathrm{Nb}$ radiation from neutron-irradiated $\mathrm{Zr}-2.5 \mathrm{wt} . \% \mathrm{Nb}$ [32] and ZIRLO $^{\mathrm{TM}}$ [33], the Zircaloy-2 studied here was of low enough activity for this to be unnecessary. In order to observe crystallographic nano-clustering in the matrix, it was necessary to obtain spectral images from high symmetry orientations. Fe/X (X $=\mathrm{Cr}, \mathrm{Ni}$, depending on SPP type) atomic ratio maps from SPPs were obtained by quantifying the spectral image in terms of atomic per cent (at.\%) and dividing the $\mathrm{Fe}$ concentration within a pixel by the concentration of alloying element $\mathrm{X}$, assuming that the concentration of $\mathrm{Zr}+\mathrm{Sn}+\mathrm{Fe}+$ $\mathrm{Cr}+\mathrm{Ni}=100 \%$ and, as such, ignoring the detection of impurity elements or thin foil surface oxide. As the matrix is relatively low in $\mathrm{Fe}, \mathrm{Cr}, \mathrm{Ni}$ the $\mathrm{Fe} / \mathrm{X}$ ratio is thought to be representative of the SPP given that analyses were obtained from particles in thin regions with little matrix contribution. The $\mathrm{Fe} / \mathrm{X}$ ratio maps were calculated after averaging $4 \times 4$ pixels, such that the spatial resolution is a quarter that of the original spectral image. All data for semi-quantification were obtained for at least 30 minutes at an X-ray detection rate of $\sim 20 \mathrm{kcps}$ such that error in quantification of $\mathrm{Fe} / \mathrm{X}$ is due largely to the calculation of the $k$-factor and is considered as $\pm 10 \%$ [34]. The average composition of an SPP was obtained by selecting all pixels containing a concentration above background ( $>\sim 1$ at. $\%$ ).

\section{Results}

\subsection{SPP dissolution}

Low magnification spectral imaging was used as a diagnostic tool for identifying areas of interest, as small regions of chemical segregation are commonly overlooked by traditional bright field imaging methods where irradiation-induced dislocation strain in the matrix can cause second phase particle (SPP) contrast to be masked. An overview of SPPs in a typical sample of nonirradiated Zircaloy-2 is provided in Figure 1, in which the dark central grain has its surface normal parallel to the direction. The different size and number densities observed for $\mathrm{Fe}-\mathrm{Cr}$ and $\mathrm{Fe}-\mathrm{Ni}$ type SPPs are immediately obvious, the latter being larger and in fewer number. There is no obvious relationship between SPP shape and matrix orientation when spectral imaging is performed from the $\langle 11 \overline{2} 0\rangle$ and $\langle 0001\rangle$ matrix orientations, only the former of which is shown here. Electropolishing-induced hydrides can be seen nucleating parallel to the basal plane (vertically) in Figure 1a, highlighted by depletions in contrast within the $\mathrm{Zr}$ map. Interestingly, the electropolishing-induced hydrides nucleate preferentially at the $\alpha-\mathrm{Zr}$ grain boundaries and at the Fe-Ni SPP-matrix interfacial region, but rarely at the Fe-Cr SPP-matrix interfacial region. 

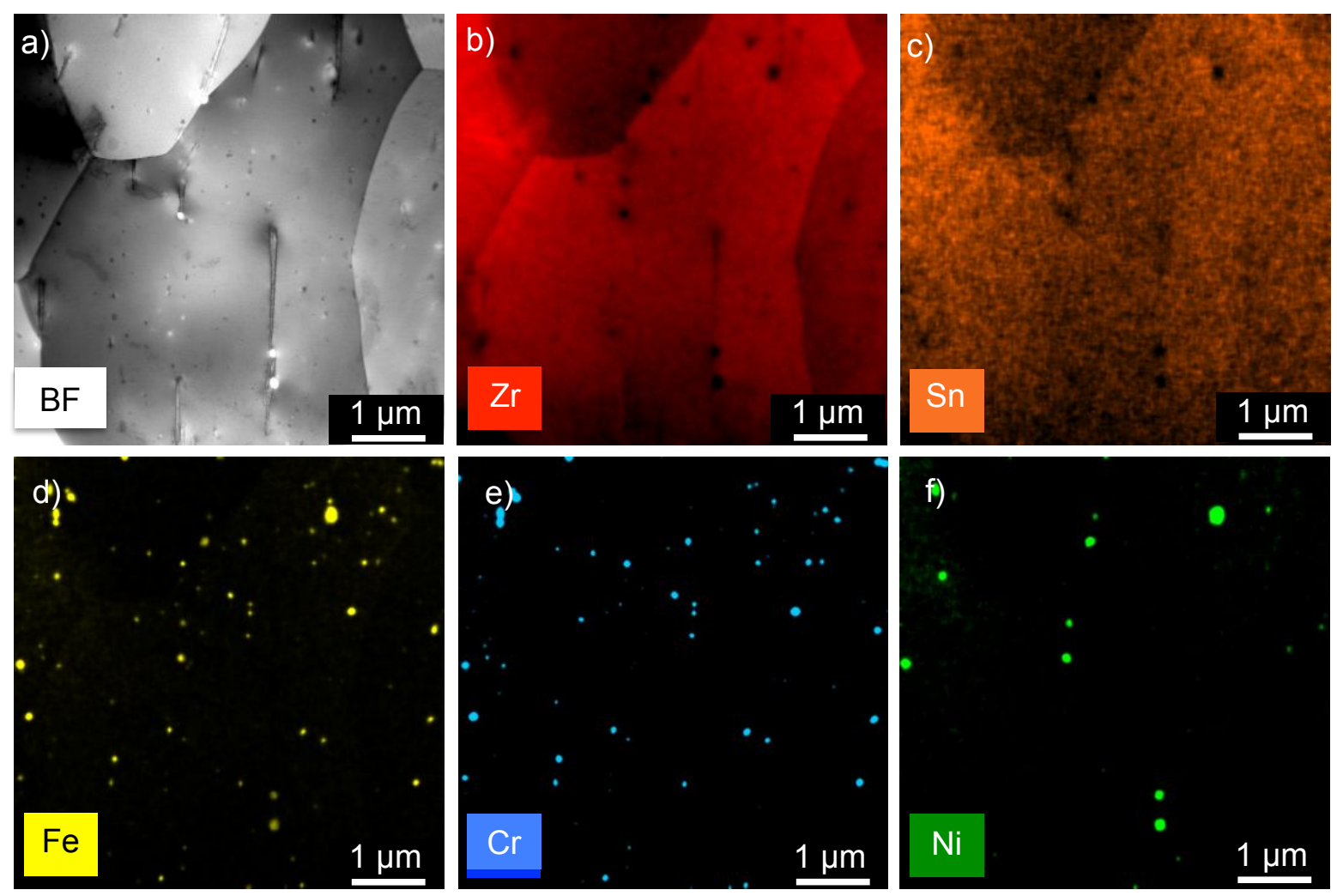

Figure 1 A typical grain shown in the BF STEM image of a) is at the $\langle 11 \overline{2} 0\rangle$ orientation, the $\langle 1 \overline{1} 00\rangle$ direction vertical and the $<0001>$ horizontal. The corresponding chemical maps are shown for $\mathrm{Zr}$, Sn, Fe, $\mathrm{Cr}$ and $\mathrm{Ni}$ in b)-f), respectively. Each chemical map is displayed in raw counts and is individually scaled with no background subtraction.

A higher magnification (320kx) BF-STEM image of a typical Fe-Cr SPP in non-irradiated Zircaloy2 is shown in Figure 2 together with the relevant chemical maps. The maps are quantified in terms of atomic per cent (at.\%) and are plotted on individual colour scales to reveal various details. For instance, the $\mathrm{Zr}$ map indicates the projected shape of the SPP in the third spatial dimension, a detail usually lost in transmission techniques without tomographic reconstruction. The Sn map also reflects the SPP shape but levels of Sn should only be considered qualitative due to the absorption of the low energy $\mathrm{Sn} \operatorname{L} \alpha$ X-ray. Interestingly, the $\mathrm{Fe}$ and $\mathrm{Cr}$ maps demonstrate spatial differences in their distribution, even before irradiation. A small amount of $\mathrm{Ni}$ was detected in all non-irradiated Fe-Cr SPPs studied. In Figure $2 \mathrm{f}$, the location of the $\mathrm{Ni}$ is coincident with the region of higher $\mathrm{Fe}$ concentration relative to $\mathrm{Cr}$.

In a similar manner to that in Figure 2, Figure 3 provides a BF-STEM image and the relevant chemical maps for a typical Fe-Ni SPP in non-irradiated Zircaloy-2. No $\mathrm{Cr}$ was detected within any of the Fe-Ni SPPs studied. Furthermore, the regions of highest concentration in $\mathrm{Fe}$ and $\mathrm{Ni}$ seem to be coincident.

To more easily compare $\mathrm{Fe}$ and $\mathrm{Cr}$ distributions within $\mathrm{Fe}-\mathrm{Cr}$ SPPs, $\mathrm{Fe} / \mathrm{Cr}$ maps were calculated such that the $\mathrm{Fe}$ or $\mathrm{Cr}$ content in a pixel must be $\geq 1$ at. $\%$ for the $\mathrm{Fe} / \mathrm{Cr}$ ratio to be displayed. The $\mathrm{Fe} / \mathrm{Cr}$ ratio maps in Figure $4 \mathrm{a}-\mathrm{d}$, show a change in the distribution of Fe relative to $\mathrm{Cr}$ in the non-irradiated state and after protonirradiation to $2.3,4.7$ and $7.0 \mathrm{dpa}$, respectively. The reader should note that the colour scale has been adjusted for the different SPPs to highlight details. A core-edge structure is formed in the Fe$\mathrm{Cr}$ SPPs during proton irradiation. The initial development of this can be seen in Figure $4 b$, which increases in clarity at the higher dose levels. 

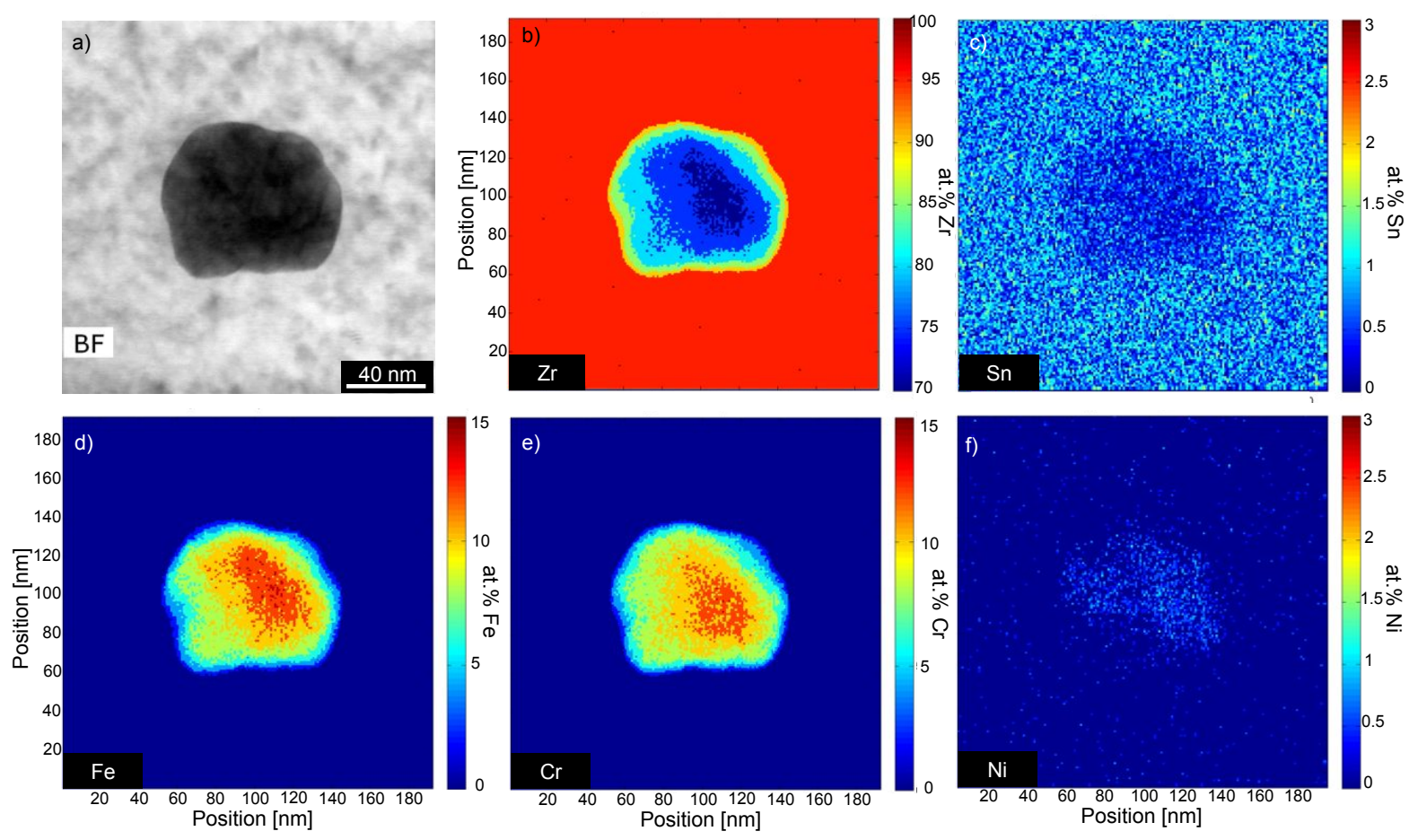

Figure 2 A single Fe-Cr Laves phase SPP in non-irradiated Zircaloy-2 is displayed in terms of its chemistry, each chemical map having its own colour scale indicating atomic per cent (at.\%) concentration. The BF STEM image is shown in a). The Zr, $\mathrm{Sn}, \mathrm{Fe}, \mathrm{Cr}$ and Ni maps are shown in b)-f), respectively.
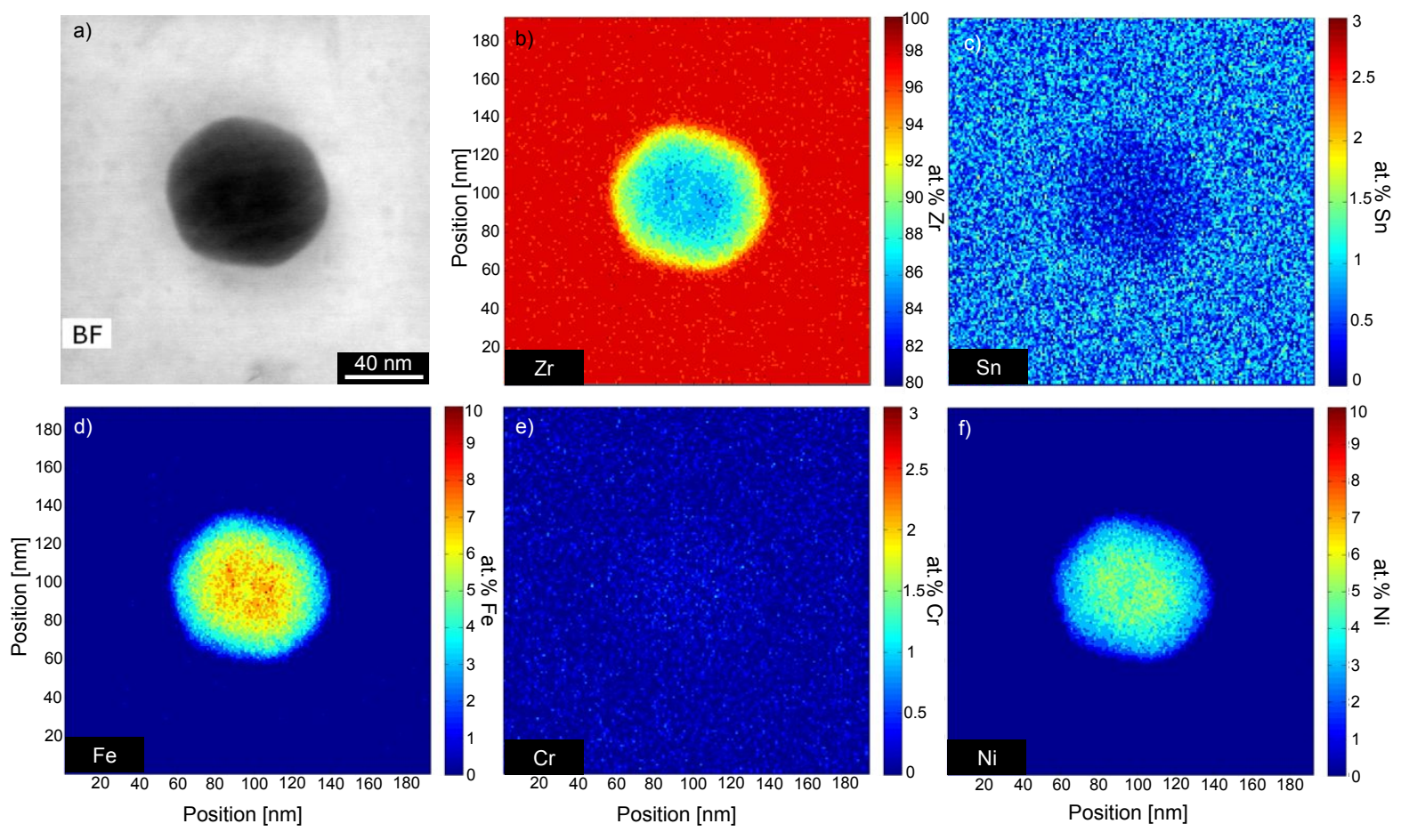

Figure 3 A single Fe-Ni SPP in non-irradiated Zircaloy-2 is displayed in terms of its chemistry, each chemical map having its own colour scale indicating atomic per cent (at.\%) concentration. The BF STEM image is shown in a). The $\mathrm{Zr}, \mathrm{Sn}, \mathrm{Fe}, \mathrm{Cr}$ and Ni maps are shown in b)-f), respectively. 


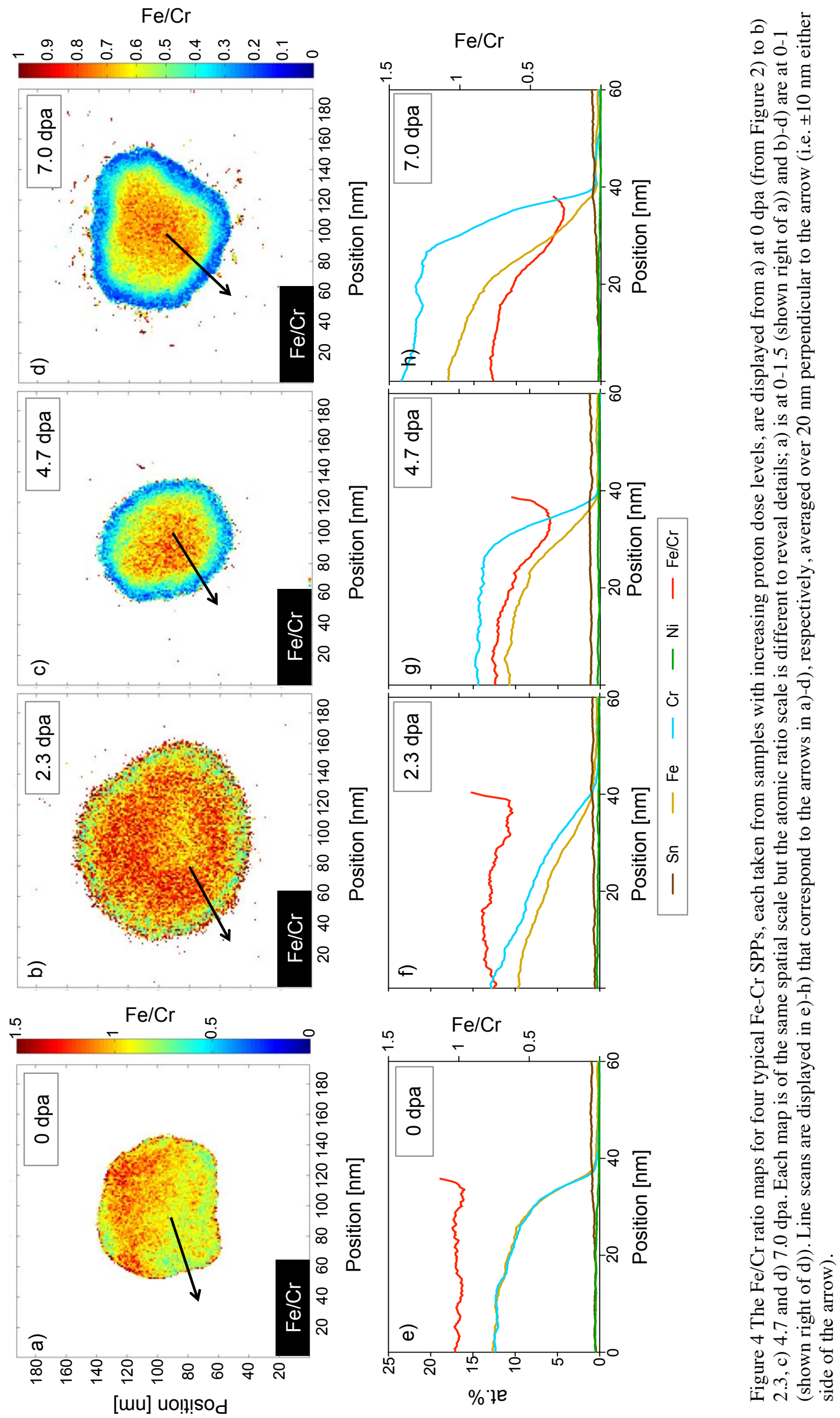


$\mathrm{Fe} / \mathrm{Ni}$
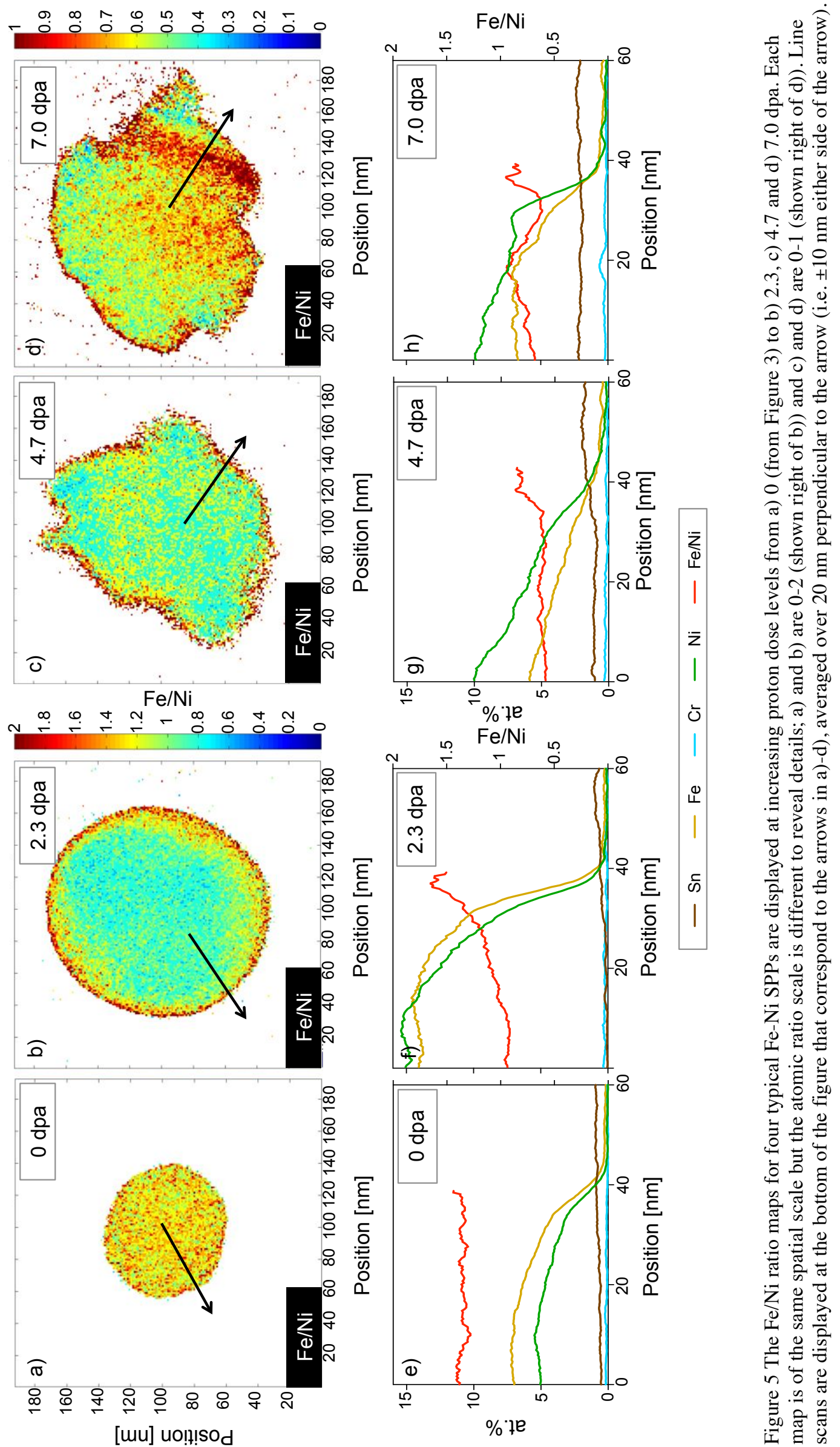
Line scans quantified in terms of at.\% are shown in Figure $4 \mathrm{f}-\mathrm{h}$ which indicate that this edge region occurs due to a decrease in the Fe content relative to the Cr. Despite this observed depletion of $\mathrm{Fe}$, all $\mathrm{Fe}-\mathrm{Cr}$ SPPs at all proton dose levels were fully crystalline and no amorphisation was observed in the Fe-depleted edge regions.

In a similar manner to that in Figure 4, Figure 5 demonstrates typical $\mathrm{Fe} / \mathrm{Ni}$ ratio maps for the Fe-Ni type SPP after proton-irradiation to 0, 2.3, 4.7 and 7.0 dpa. Unlike the Fe-Cr type SPPs, the Fe-Ni type does not show a clear edge-core structure. While the very periphery of the irradiated $\mathrm{Fe}-\mathrm{Ni}$ SPPs seem to have a higher $\mathrm{Fe} / \mathrm{Ni}$ ratio than the rest of the SPP, there is no significant Fe peak at the interface and the counts in this region are very low. The shape of the Fe-Ni SPPs are irregular at proton irradiation doses 4.7 and $7.0 \mathrm{dpa}$. Interestingly, at the highest proton dose a channel of $\mathrm{Fe} / \mathrm{Ni} \sim 1$ is observed close to the edge of the SPP, Figure 5d, while most of the inner part of this SPP has a much lower ratio. All Fe-Ni SPPs at all doses in the proton-irradiated material were fully crystalline.
The data in Figure 6 presents a summary of the maps in Figure 4a-d and Figure 5a-d on the same spatial and $\mathrm{Fe} / \mathrm{X}(\mathrm{X}=\mathrm{Cr}, \mathrm{Ni})$ scales. The figure contains the eight histograms of the $\mathrm{Fe} / \mathrm{X}$ ratios in the previous two figures, which have each been plotted as a line graphic for a greater ease of comparison, binned in $\mathrm{Fe} / \mathrm{X}$ increments of 0.05 . The evolution towards a bimodality of the $\mathrm{Fe} / \mathrm{Cr}$ ratio is clear from this data, as is the lack of such a feature in the $\mathrm{Fe} / \mathrm{Ni}$ ratio. The $\mathrm{Fe} / \mathrm{Cr}$ bimodality values remain almost the same between 4.7 and 7.0 dpa. a) Fe/Cr Ratio Distribution, Fe-Cr SPP

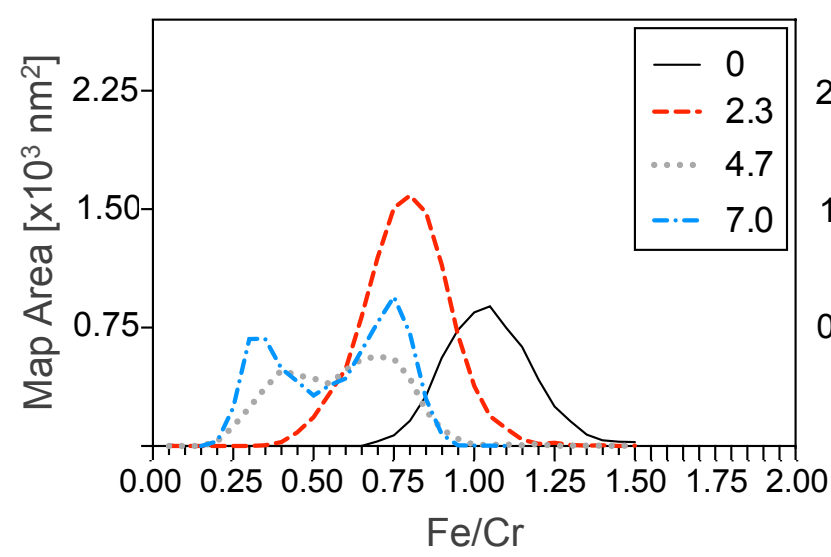

b) Fe/Ni Ratio Distribution, Fe-Ni SPP

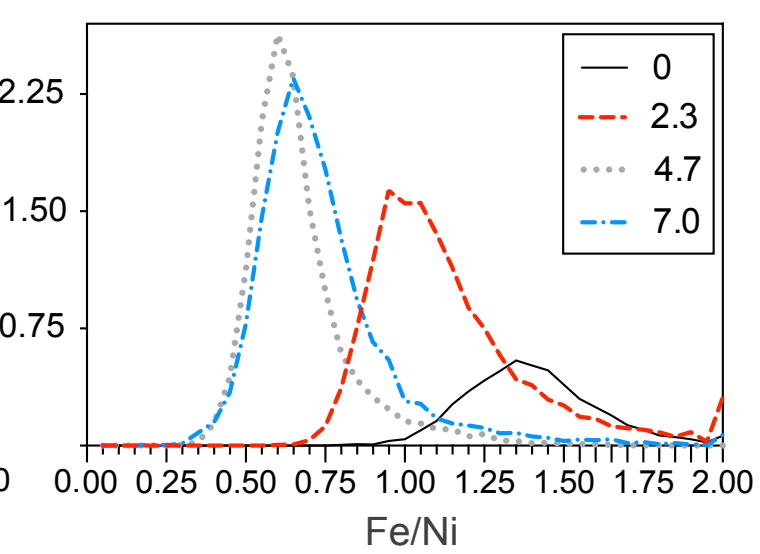

Figure 6 A histogram of the area in Figure 4 a)-d) and Figure 5 a)-d), displayed in a) and b), respectively, to act as a summary of those previous figures. The histograms are displayed as a line graphic for ease of comparison, binned in Fe/X $(\mathrm{X}=\mathrm{Cr}, \mathrm{Ni}$ ) increments of 0.05 , corresponding to $0,2.3,4.7$ and $7.0 \mathrm{dpa}$. The differences in the area under each curve are due to differences in SPP size. 

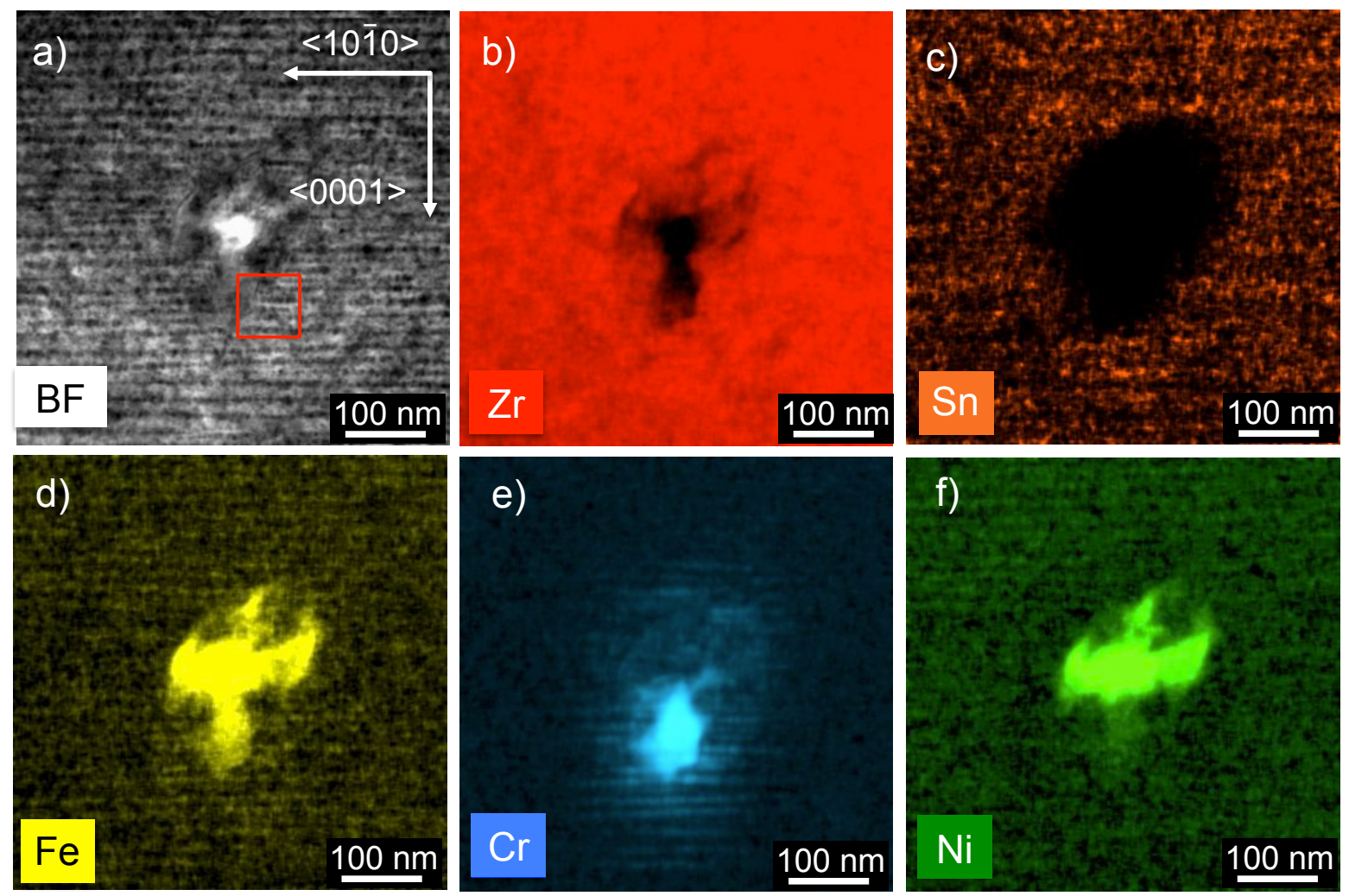

Figure 7 The zone axis $\langle 11 \overline{2} 0\rangle$ BF STEM image and $\mathrm{Zr}, \mathrm{Sn}, \mathrm{Fe}, \mathrm{Cr}$ and Ni chemical maps are displayed in a)-f), receptively for an dissolving SPP with both Fe-Cr and Fe-Ni SPP regions, irradiated in a BWR clad to a fluence of $14.7 \times 10^{25} \mathrm{n} \mathrm{m}^{-2} \sim 24.5$ dpa. The red box in a) indicates the region for higher magnification chemical mapping in Figure 8.

A similar analysis has been performed for the neutron-irradiated material, but the semiquantification performed for the proton-irradiated material proved unsuitable due to the higher dose of the material $\left(>8.7 \times 10^{25} \mathrm{n} \mathrm{m}^{-2} \sim 14.5 \mathrm{dpa}\right)$ and the correspondingly lower concentration of alloying elements within SPPs. Alternatively, Figure 7 displays a partially dissolved SPP with both $\mathrm{Fe}-\mathrm{Cr}$ and $\mathrm{Fe}-\mathrm{Ni}$ regions in Zircaloy-2, neutron-irradiated to the highest fluence in this study, $14.7 \times 10^{25} \mathrm{n} \mathrm{m}^{-2} \sim 24.5 \mathrm{dpa}$. The figure shows the BF STEM image from the direction in Figure $7 \mathrm{a}$ and the $\mathrm{Zr}, \mathrm{Sn}, \mathrm{Fe}, \mathrm{Cr}$ and $\mathrm{Ni}$ maps in parts b-f, respectively, as raw images displaying $X$-ray counts, individually scaled. The BF STEM image in Figure 7a shows c-component dislocation loops (c-loops) lying parallel to the trace of the basal plane (horizontal). While the SPP shape is difficult to discern from the BF STEM image due to the c-loop strain contrast, the chemical maps reveal the SPP shape clearly. The $\mathrm{Fe}-\mathrm{Ni}$ SPP is of an irregular shape, whilst the FeCr SPP retains spheroidal character but with uneven peripheries. Some alignment of $\mathrm{Sn}, \mathrm{Fe}, \mathrm{Cr}$ and $\mathrm{Ni}$ can be seen parallel to the trace of the basal plane in the matrix, but this is more evident for $\mathrm{Cr}$ in close proximity to the SPP (Figure 7e), where segregation to c-loop positions is observed. While the $\mathrm{Sn}$ map demonstrates depletion in a region larger than the size of the dissolving SPP, the $\mathrm{Zr}$ map is almost perfectly anti-correlated with the sum of the $\mathrm{Fe}, \mathrm{Cr}$ and $\mathrm{Ni}$ maps.

A quantification was attempted of the small region highlighted by the red square in Figure 7a so that an Fe/Cr map could be calculated. The raw images displaying X-ray counts, individually scaled, are presented in Figure 8a and $\mathrm{b}$, in which the $\mathrm{Fe}$ and $\mathrm{Cr}$ maps are shown, respectively, and the quantified $\mathrm{Fe} / \mathrm{Cr}$ atomic ratio map is given in Figure 8c. The segregation of Fe and $\mathrm{Cr}$ to the c-loops surrounding the SPP is discontinuous when observed from the zone axis, forming what seems to be nano-clusters or nanoprecipitates. As a crystallographic analysis was not performed on this segregation, it shall be referred to as nano-clustering. The $\mathrm{Fe} / \mathrm{Cr}$ map demonstrates that both the SPP and the nanoclustering close to the SPP are severely depleted 
in $\mathrm{Fe}$ relative to $\mathrm{Cr}$. However, $\mathrm{Cr}$ does not extend far into the matrix and so the nano-clusters become depleted in $\mathrm{Cr}$ at a distance of $30-50 \mathrm{~nm}$.
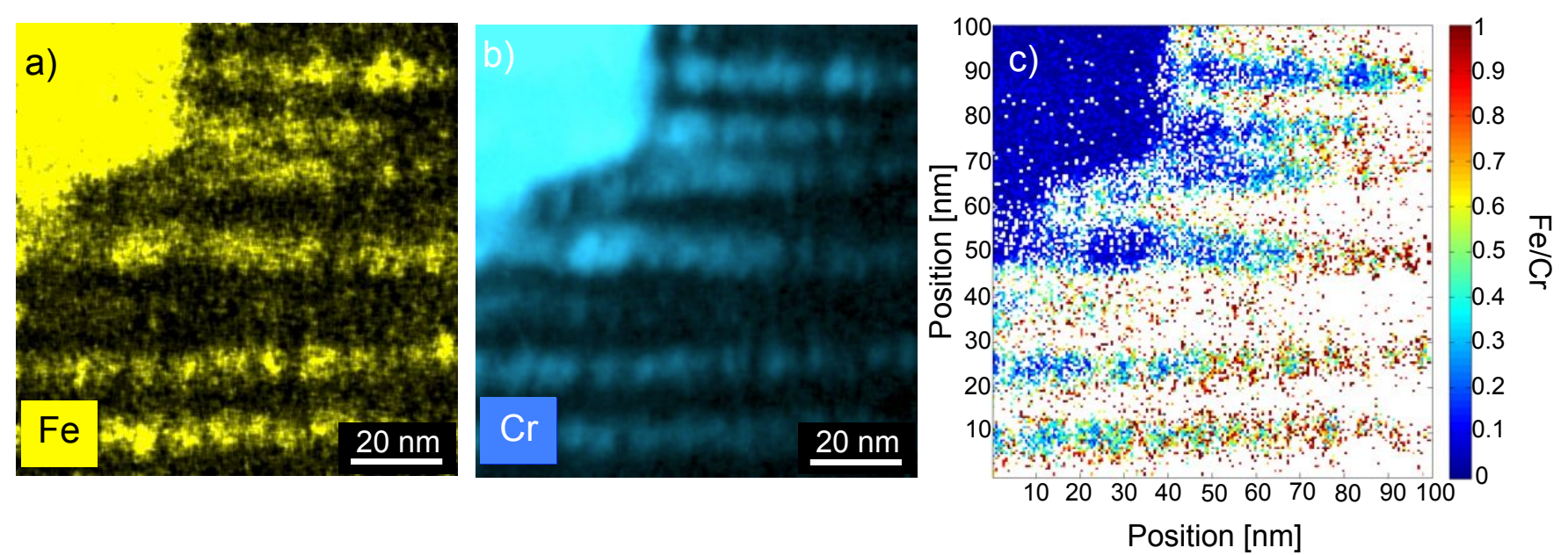

Figure $8 \mathrm{The} \mathrm{Fe}$ and $\mathrm{Cr}$ maps are shown in a) and b), respectively, for the region highlighted by a red square in Figure $7 \mathrm{a}$ at the same matrix orientation $\langle 11 \overline{2} 0\rangle$. Each chemical map is displayed in raw counts and is individually scaled. These maps were quantified in at.\% and the atomic fraction $\mathrm{Fe} / \mathrm{Cr}$ map in c) was calculated.
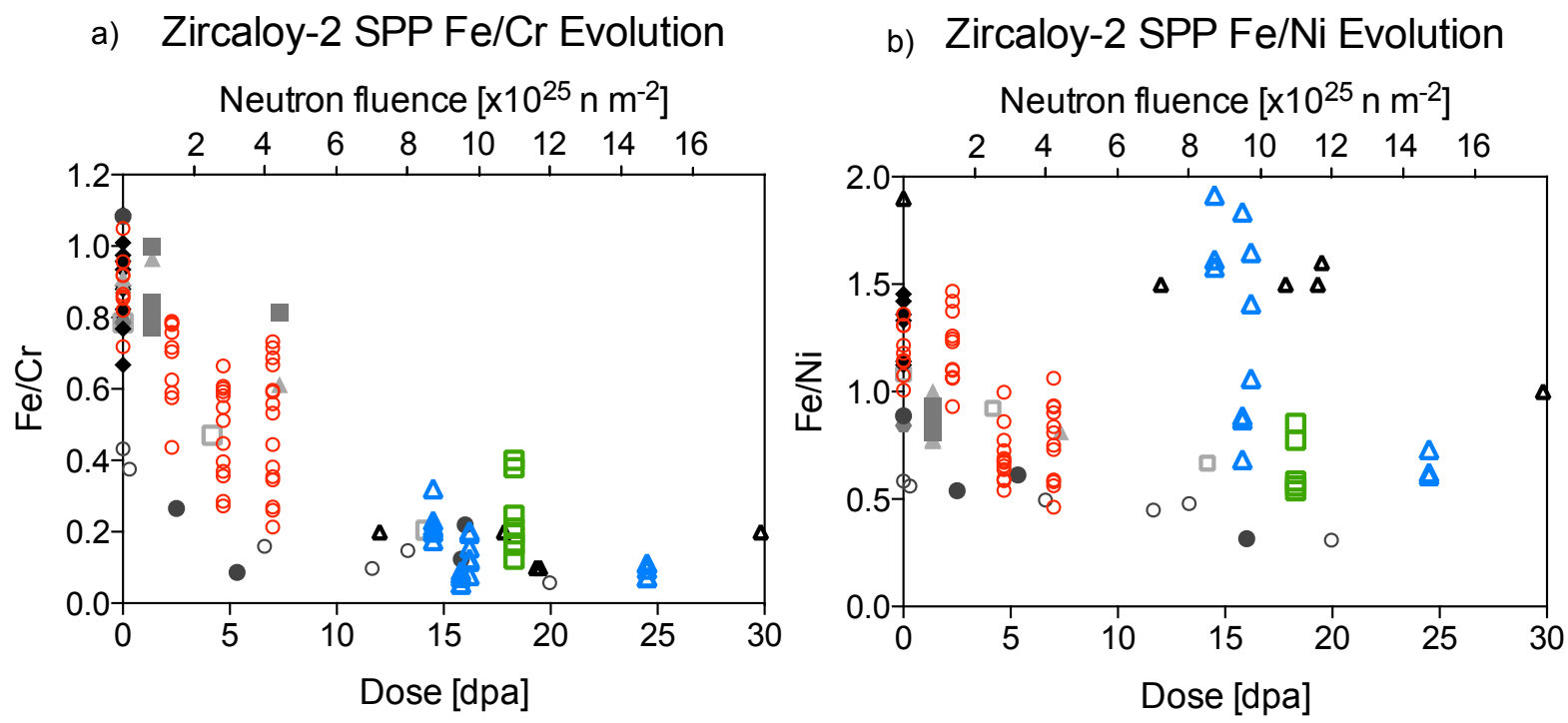

\begin{tabular}{|llllllll|}
\hline$\circ$ & ${ }^{*}$ Proton $350^{\circ} \mathrm{C}$ & $\bullet$ & Goll 2002 & $\bullet$ & Sawabe 2013 & 口 & Huang 1996 \\
$\square$ & ${ }^{*}$ BWR Channel & $\bullet$ & Cockeram 2013 & $\bullet$ & Meng 1989 & $\Delta$ & Valizadeh 2014 \\
$\Delta$ & ${ }^{*}$ BWR Clad & $\Delta$ & Cockeram 2013 & $\circ$ & Etoh 1993 & & \\
\hline
\end{tabular}

Figure 9 The variation with irradiation dose in the $\mathrm{Fe} / \mathrm{Cr}$ and the $\mathrm{Fe} / \mathrm{Ni}$ ratio for $\mathrm{Fe}-\mathrm{Cr}$ and $\mathrm{Fe}-\mathrm{Ni}$ SPPs is shown in a) and b), respectively, with ' $*$ ' indicating the present study. All literature values are taken from BWR-irradiated Zircaloy-2 with the exception of Cockeram 2013 from a test HFIR reactor. Literature values were obtained by STEM EDS by [9], [35] for $\alpha$ annealed and $\beta$-treated material as squares and triangles, respectively, [10], [42], [49] and [12] , and analysis by atom probe tomography by [69]. 
Although quantification maps in the neutron-irradiated material demonstrated a lot of noise due to low concentrations in the transmission direction, obtaining the average concentration of all pixels with an alloying element concentration above background $(>\sim 1$ at.\%) at high magnification after long counting times (> 30 minutes at $20 \mathrm{kcps}$ ) gave reliable $\mathrm{Fe} / \mathrm{X}$ $(\mathrm{X}=\mathrm{Cr}, \mathrm{Ni})$ ratios. This was accomplished for both proton- and neutron-irradiated material by selecting all pixels corresponding to $\mathrm{Fe}, \mathrm{Cr}$ or $\mathrm{Ni}$ concentrations above background ( $>\sim 1$ at. $\%$ ). The variation in the $\mathrm{Fe} / \mathrm{X}$ atomic ratio with increasing proton and neutron dose can be seen in Figure 9a and $b$, in which the individual SPPs are shown to display the scatter in the data. In total, $97 \mathrm{Fe}-\mathrm{Cr}$ SPPs and $64 \mathrm{Fe}-\mathrm{Ni}$ SPPs were analysed in this way. There is a general decrease in the $\mathrm{Fe} / \mathrm{Cr}$ ratio with increasing proton dose, the mean values for which are given in Table 1. This decreasing trend is continued in the higher dose neutron-irradiated SPPs. In a similar manner to the $\mathrm{Fe} / \mathrm{Cr}$ data, Figure $9 \mathrm{~b}$ displays a general decrease in $\mathrm{Fe} / \mathrm{Ni}$ ratio with increasing proton and neutron dose. However, the trend is not continuous between the proton- and neutron-irradiated material as in the $\mathrm{Fe} / \mathrm{Cr}$. The mean $\mathrm{Fe} / \mathrm{Ni}$ ratios for the various proton and neutron dose levels are also given in Table 1.

Table 1 The mean $\mathrm{Fe} / \mathrm{Cr}$ and $\mathrm{Fe} / \mathrm{Ni}$ atomic ratios for $\mathrm{Fe}-\mathrm{Cr}$ and Fe-Ni SPPs after proton irradiation between 2.3 and 7.0 dpa at $350{ }^{\circ} \mathrm{C}$ and for neutron irradiation between $\sim 14.5$ and $\sim 24.5 \mathrm{dpa}\left(8.7\right.$ to $14.7 \times 10^{25} \mathrm{n} \mathrm{m}^{-2}$ ) in a BWR. The error given is a single standard deviation from the mean. The number in parentheses is the number of SPPs studied.

\begin{tabular}{llrlr}
\hline Dose [dpa] & \multicolumn{3}{l}{ Mean Fe/Cr } & \multicolumn{1}{l}{ Mean Fe/Ni } \\
\hline 0 & $0.86 \pm 0.07$ & $(8)$ & $1.19 \pm 0.12$ & $(9)$ \\
2.3 & $0.68 \pm 0.01$ & $(10)$ & $1.19 \pm 0.17$ & $(12)$ \\
4.7 & $0.48 \pm 0.13$ & $(13)$ & $0.70 \pm 0.13$ & $(12)$ \\
7.0 & $0.49 \pm 0.18$ & $(15)$ & $0.76 \pm 0.18$ & $(12)$ \\
14.5 & $0.22 \pm 0.05$ & $(6)$ & $1.70 \pm 0.18$ & $(3)$ \\
15.8 & $0.07 \pm 0.01$ & $(6)$ & $1.07 \pm 0.52$ & $(4)$ \\
16.2 & $0.14 \pm 0.04$ & $(13)$ & $1.55 \pm 0.42$ & $(4)$ \\
18.3 & $0.24 \pm 0.10$ & $(16)$ & $0.66 \pm 0.14$ & $(5)$ \\
24.5 & $0.09 \pm 0.02$ & $(10)$ & $0.65 \pm 0.07$ & $(3)$ \\
\hline
\end{tabular}

There is considerable scatter in the measurements presented here for $\mathrm{Fe} / \mathrm{Cr}$ and $\mathrm{Fe} / \mathrm{Ni}$ in the proton-irradiated Zircaloy-2, although most measurements agree with the neutron-irradiated measurements from the literature included in Figure 9 for the low fluence levels. All literature data points are from Zircaloy-2 irradiated in a BWR at nominally $\sim 300{ }^{\circ} \mathrm{C}$ with the exception of those from Cockeram et al., which were irradiated in neutron test reactor HFIR at $\sim 358^{\circ} \mathrm{C}$ [35]. First we will consider the $\mathrm{Fe}-\mathrm{Cr}$ system. The scatter in the $\mathrm{Fe} / \mathrm{Cr}$ measurements may be explained by consideration of the size and chemistry of the Fedepleted edge region of the Fe-Cr SPP and with reference to Figure 10. It can be seen from Figure $10 \mathrm{a}$ that the $\mathrm{Fe} / \mathrm{Cr}$ in the edge region is positively correlated with the $\mathrm{Fe} / \mathrm{Cr}$ in the core region of the SPP, and it can be seen from Figure 10b that the size of the edge region is positively correlated with the size of the whole SPP. With reference to Figure $10 \mathrm{a}$, the ratio of $(\mathrm{Fe} / \mathrm{Cr}$ edge $):(\mathrm{Fe} / \mathrm{Cr}$ core $)$ is $\sim 1.01$ at $2.3 \mathrm{dpa}, \sim 0.74$ at $4.7 \mathrm{dpa}$ and $\sim 0.75$ at 7.0 dpa. With reference to Figure 10b, the fraction of the edge width with respect to the whole SPP radius increases from $\sim 0.42$ at 2.3 dpa to $\sim 0.49$ at $4.7 \mathrm{dpa}$ and $\sim 0.73$ at $7.0 \mathrm{dpa}$. In comparing Figure $10 \mathrm{a}$ and $\mathrm{b}$, the most significant amount of $\mathrm{Fe}$ depletion occurs between 2.3 and 4.7 dpa but an acceleration in edge size occurs between 4.7 and 7.0 dpa. The scatter in the average SPP $\mathrm{Fe} / \mathrm{Cr}$ measurements in Figure 9a can be explained by the variable SPP size in the non-irradiated material; large SPPs at 7.0 dpa are able to retain a core region of sufficient size to give an $\mathrm{Fe} / \mathrm{Cr}$ averaged over he whole SPP that is similar to that observed in the non-irradiated state.

The average effect of SPP size on the change in $\mathrm{Fe} / \mathrm{Cr}$ ratio is shown in Figure 11a and b. These figures display the $\mathrm{Fe} / \mathrm{Cr}$ averaged over the whole SPP and its variation with the effective SPP radius, $\mathrm{r}=(\mathrm{A} / \pi) 0.5$, where $\mathrm{A}$ is the SPP area as determined by EDS spectral imaging. The mean $\mathrm{Fe} / \mathrm{Cr}$ ratios in the core and edge regions are given in Table 2 in addition to the mean core and edge sizes at each proton dose level. While no variation in the $\mathrm{Fe} / \mathrm{Cr}$ ratio was observed with SPP size in the non-irradiated material, the $\mathrm{Fe} / \mathrm{Cr}$ in the core region alone is shown to increase with SPP size at all dose levels indicating that although $\mathrm{Fe}$ depletion is occurring from the edge preferentially, 

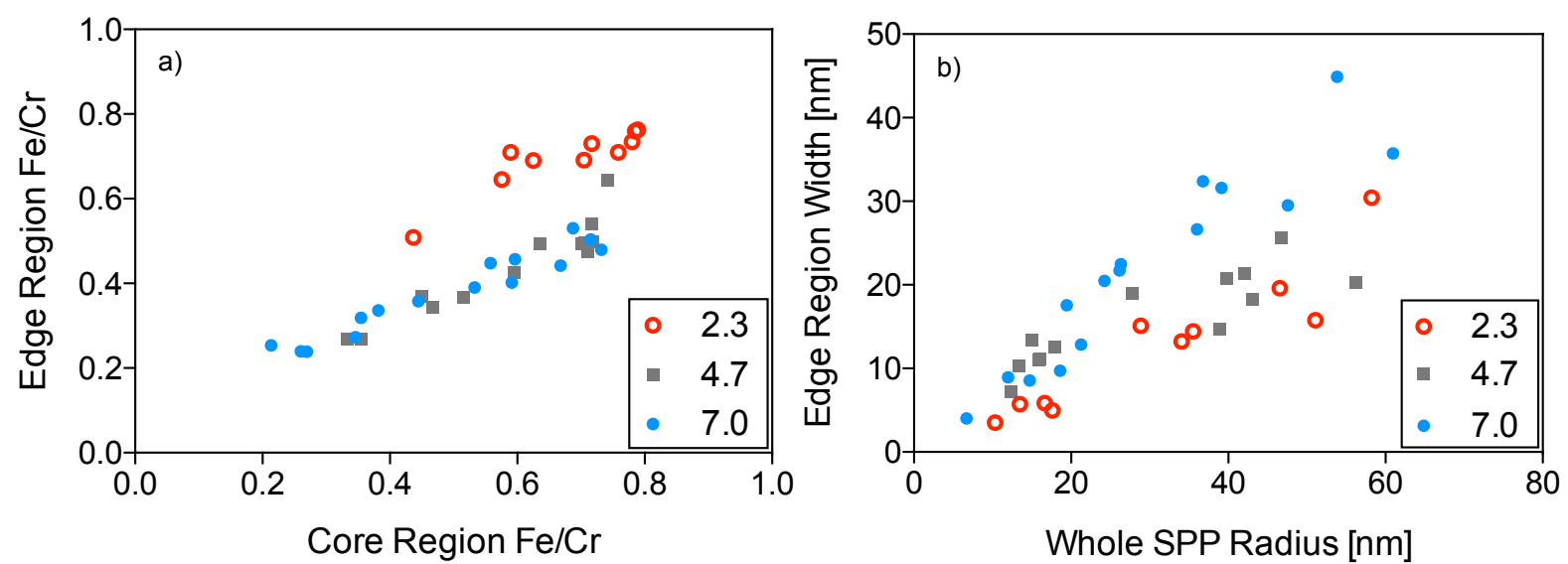

Figure 10 The relationship between the $\mathrm{Fe} / \mathrm{Cr}$ atomic ratio in the core and edge regions of $\mathrm{Fe}-\mathrm{Cr}$ SPPs at various proton dose levels in displayed in a) and the relationship between the width of the edge region and the radius of the whole Fe-Cr SPP at various proton dose levels is displayed in b).
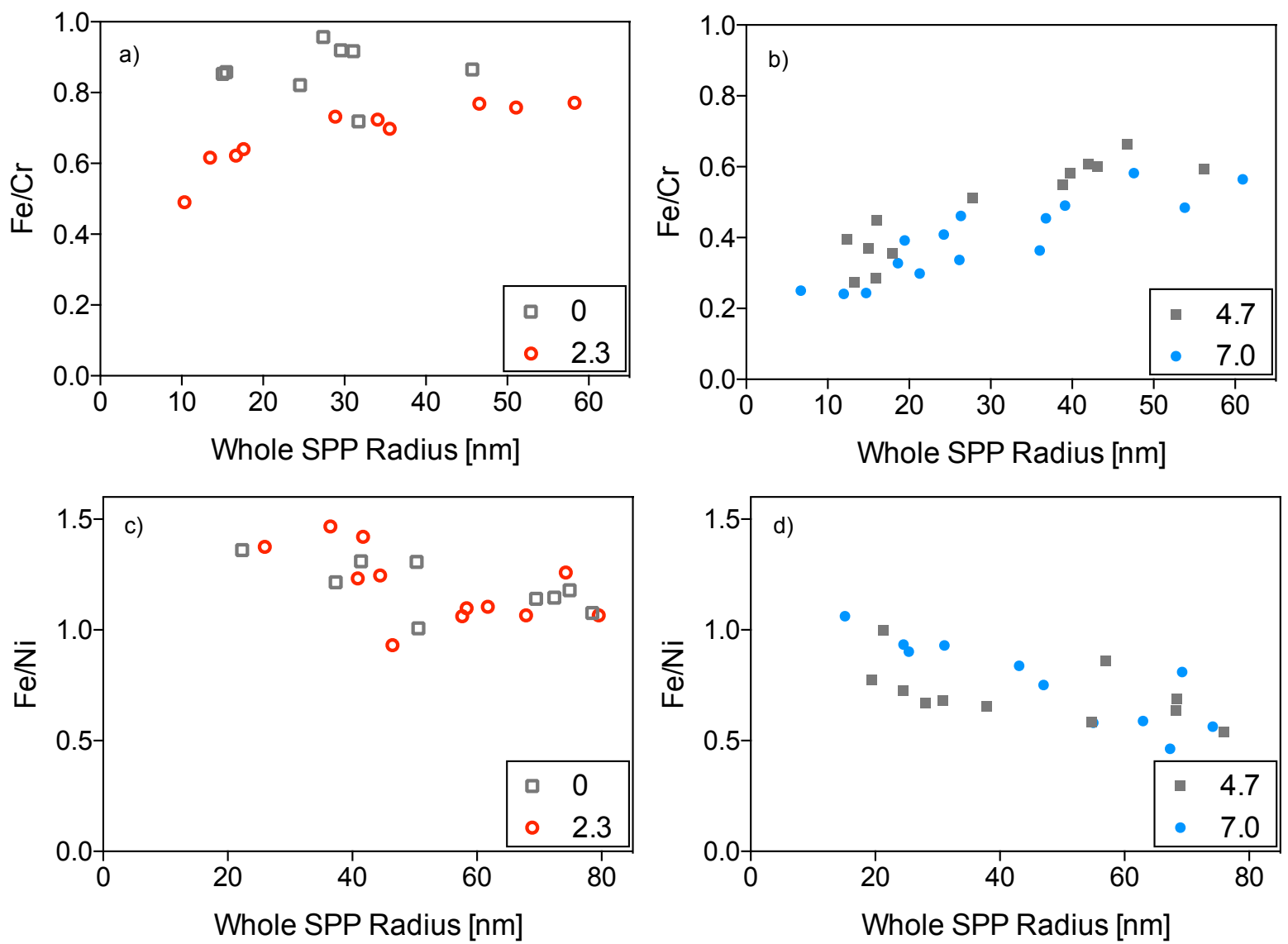

Figure 11 The scatter in $\mathrm{Fe} / \mathrm{X}(\mathrm{X}=\mathrm{Cr}, \mathrm{Ni})$ determination is displayed for the proton data in relation to the effective radius of the whole SPP, $r=(\mathrm{A} / \pi) 0.5$, where $\mathrm{A}$ is the area of the (rarely circular) SPP. The figure shows the $\mathrm{Fe} / \mathrm{Cr}$ at a) 0 and $2.3 \mathrm{dpa}, \mathrm{b}$ ) 4.7 and $7.0 \mathrm{dpa}$, and for $\mathrm{Fe} / \mathrm{Ni}$ at c) 0 and $2.3 \mathrm{dpa}$ and d) 4.7 and $7.0 \mathrm{dpa}$. 
Table 2 The edge and core properties of Fe-Cr SPPs after proton irradiation to 2.3, 4.7 and 7.0 dpa are detailed with variation given as \pm a single standard deviation from the mean. The non-irradiated SPP has a mean Fe/Cr ratio of $0.86 \pm 0.07$ with no edge structure. The edge radius varies linearly with the radius of the whole SPP and the relationship is given by the ratio Edge/Whole.

\begin{tabular}{llllll}
\multicolumn{3}{l}{ Mean Radius } & \multicolumn{5}{l}{ Fe/Cr Ratio } \\
Proton Dose [dpa] & Edge/Whole & Edge [nm] & Core/Edge & Core & Edge \\
\hline 2.3 & 0.42 & $13 \pm 8$ & $\sim 1$ & $0.68 \pm 0.12$ & $0.69 \pm 0.07$ \\
4.7 & 0.49 & $16 \pm 5$ & 1.35 & $0.59 \pm 0.15$ & $0.43 \pm 0.11$ \\
7.0 & 0.73 & $22 \pm 12$ & 1.30 & $0.49 \pm 0.18$ & $0.38 \pm 0.10$ \\
\hline
\end{tabular}

there is some dissolution from the core region. In support of this, the decrease in the $\mathrm{Fe} / \mathrm{Cr}$ ratio with respect to proton dose is larger in the edge region than in the core. This effect is smaller as the SPP size increases. Unfortunately, in the neutronirradiated material, due to the higher dose levels and consistently low $\mathrm{Fe} / \mathrm{Cr}$ throughout the whole SPP, such an analysis with respect to SPP size was not possible.

As no clear edge-core structure was observed for the Fe-Ni SPPs, such an analysis cannot be used to explain the scatter in the $\mathrm{Fe} / \mathrm{Ni}$ measurements displayed in Figure 9. However, the $\mathrm{Fe} / \mathrm{Ni}$ has been plotted as a function of the effective SPP radius in Figure 11c and $d$. Interestingly, all $\mathrm{Fe}-\mathrm{Ni} \mathrm{SPPs}$ at all proton dose levels show a similar decrease in the $\mathrm{Fe} / \mathrm{Ni}$ atomic ratio with increasing SPP size.

\section{Discussion}

\subsection{SPP dissolution}

\subsubsection{Internal SPP diffusional capacity and homogeneity}

In comparing the chemical maps of the non-irradiated $\mathrm{Fe}-\mathrm{Cr}$ and $\mathrm{Fe}-\mathrm{Ni} \mathrm{SPPs}$ in Figure 2 and Figure 3, respectfully, one may draw conclusions about the self-diffusivity of components within the different SPP types. While stereomicroscopy and elemental mapping as a function of tilt angle would provide more quantitative information on the 3D nature of any chemical heterogeneity, the $\mathrm{Zr}$ map in Figure $2 \mathrm{~b}$ provides information about the shape of the $\mathrm{Fe}-\mathrm{Cr}$ SPP in the transmission direction and so any other map with similar contouring might be considered to be homogeneous within the SPP. As the Fe map in Figure $2 \mathrm{~d}$ displays similar contouring to the $\mathrm{Zr}$, one might suggest that $\mathrm{Fe}$ is evenly distributed throughout the SPP. Conversely, as the Cr map in Figure 2e does not follow the $\mathrm{Zr}$ contouring, it is unevenly distributed within the SPP. An explanation for this may be found in the Ni map of Figure 2e, which is coincident with $\mathrm{Fe}$ and may result in some partitioning of the Cr. In support of this, $\mathrm{Fe}-\mathrm{Cr}$ type and $\mathrm{Fe}-\mathrm{Ni}$ type $\mathrm{SPPs}$ are commonly observed in Zircaloy-2, but $\mathrm{Cr}$ and $\mathrm{Ni}$ are never the dominating constituents. Instead, Fe$\mathrm{Cr}$ and $\mathrm{Fe}-\mathrm{Ni} \mathrm{SPP}$ clusters are known to form with orientation relationship $(1 \overline{1} 0)_{F e-N i} \|(10 \overline{1} 1)_{F e-C r}$ and $(002)_{\mathrm{Fe}-\mathrm{Ni}} \|(\overline{2} 110)_{\mathrm{Fe}-\mathrm{Cr}}$ [36], and have indeed been found in the present work, e.g. in Figure 7, although such orientation relationships have not been determined here. The Fe-Ni regions are frequently the larger of the two within an SPP cluster, suggesting that Fe-Ni SPPs act as nucleation sites for Fe-Cr SPPs. This is supported by the respective diffusivities of the elements in $\alpha-\mathrm{Zr} \mathrm{Fe}>\mathrm{Ni}>\mathrm{Cr}$ [37] such that Fe-Ni SPPs nucleate first. All of the Fe-Ni SPPs studied in the present work contained no $\mathrm{Cr}$, suggesting more chemical homogeneity in $\mathrm{Fe}-\mathrm{Ni}$ in contrast to $\mathrm{Fe}$ Cr SPPs. Such a property may be important with respect to behaviour under irradiation, as chemical mixing is thought to be the primary form of disorder in intermetallic systems [38]. Brimhall et al. have argued that a tendency for increased selfsolubility or greater stoichiometric range is a deciding factor in regards to resistance to irradiation-induced amorphisation [39]. It is wellknown that Fe-Ni SPPs resist amorphisation under neutron irradiations at intermediate temperatures, whereas $\mathrm{Fe}-\mathrm{Cr}$ SPPs do not [40]. Chemical homogeneity as a property correlated to irradiation damage resistance is shown in the lack of amorphisation in relatively pure or solid solution 
phases, such as in the $\alpha-\mathrm{Zr}$ matrix or the $\beta-\mathrm{Nb}$ phase in Zr-Nb-type alloy systems [28]. The chemical homogeneity of the Fe-Ni SPPs in comparison to the $\mathrm{Fe}-\mathrm{Cr} \mathrm{SPP}$, may suggest increased diffusional capacity within the $\mathrm{Fe}-\mathrm{Ni}$ SPP. This homogeneity may be related to its resistance to irradiation-induced amorphisation at irradiation temperatures $280-330{ }^{\circ} \mathrm{C}$ [40].

The $\mathrm{Fe}-\mathrm{Cr}$ SPP is known to become partially amorphous at typical BWR irradiation temperatures [6,40-42]. This amorphous region starts at the matrix-SPP interfacial region and progresses inwards radially at a rate $\sim 10-13 \mathrm{~nm}$ per neutron fluence $1 \times 10^{25} \mathrm{n} \mathrm{m}^{-2}$ under normal power reactor operating conditions $[40,43,44]$, but at higher rates under higher fluxes and at lower temperatures [45]. This amorphous zone is known to be depleted in Fe relative to the crystalline SPP core $[6,40-42,46]$, and so Fe depletion from the edge region into the surrounding matrix is thought to be responsible for the amorphous transformation.

\subsubsection{SPP dissolution and amorphisation}

While no amorphisation was observed in any SPP studied in the present work, Fe depletion from the edge region of $\mathrm{Fe}-\mathrm{Cr}$ SPPs is evident from the $\mathrm{Fe} / \mathrm{Cr}$ ratio maps and line scans of Figure 4. Further, Fe depletion from Fe-Ni SPPs is evidenced similarly in Figure 5. As there is $\mathrm{Fe}, \mathrm{Cr}$ and $\mathrm{Ni}$ in the $\mathrm{Zr}$ matrix below the detectable limit, the $\mathrm{Fe} / \mathrm{X}$ ratio is reliable within the SPP itself as it changes drastically towards the very interface, after which it becomes unreliable, and has been removed from the maps with the condition that for display the $\mathrm{Fe}, \mathrm{Cr}$, Ni concentration must be $\geq 1$ at.\%. As no amorphisation has been observed in the proton irradiation of the present work, thermal recovery mechanisms at the irradiation temperature of $350{ }^{\circ} \mathrm{C}$ are therefore thought to be sufficient such that the rate of annealing is equal to or greater than the rate of damage accumulation in order to avoid irradiation-induced amorphisation [38]. $\mathrm{Zu}$ et al. have studied proton irradiation damage in Zircaloy-4 under a similar damage rate and have demonstrated an amorphous rim in $\mathrm{Fe}-\mathrm{Cr} \mathrm{SPPs}$ at an irradiation temperature of $310{ }^{\circ} \mathrm{C}$ but not at $350{ }^{\circ} \mathrm{C}$ [47]. This suggests that the critical temperature for amorphisation for the Fe-Cr SPP $\left(\mathrm{T}_{\text {crit }}\right)$, above which no amorphisation occurs, is between $310^{\circ} \mathrm{C}$ and $350{ }^{\circ} \mathrm{C}$. This is in agreement with the observations presented here and similar to that under neutron irradiation at power reactor fluxes $\mathrm{T}_{\text {crit }} \sim 330-360{ }^{\circ} \mathrm{C}[40,48]$. While Griffiths et al. have suggested that the amorphisation rate in Zircaloy-2 Fe-Cr SPPs may be greater than that in Zircaloy-4 Fe-Cr SPPs due to the higher $\mathrm{Fe} / \mathrm{Cr}$ in the SPPs of the latter [40], this conclusion was drawn from materials experiencing very different neutron fluxes. Other studies have shown the rate of amorphous ingress to be similar for Zircaloy-2 Fe-Cr SPPs at $\sim 10$ per $1 \times 10^{25} \mathrm{n} \mathrm{m}^{-2}$ under BWR conditions [49]. In this regard, proton irradiation has greater similarity to neutron irradiation in comparison to electron or heavy ion irradiation, for which $\mathrm{T}_{\text {crit }}$ is equal to $\sim 30{ }^{\circ} \mathrm{C}[50]$ and $\sim 380-580{ }^{\circ} \mathrm{C}[50,51]$, respectfully, depending of course on particle flux and type of heavy ion. The reason for such discrepancies may be deduced from a consideration of the various damage rates and the nature of the damage created. Under neutron irradiation, the damage rate is equal to $\sim 0.7-1 \mathrm{x}^{-7} \mathrm{dpa} \mathrm{s}^{-1}[28,30]$. Electron irradiation may be performed at damage rates higher than neutron irradiations by a factor of $\sim 10^{5}$ [25], but the damage is in the form of isolated Frenkel pairs [52] which will not require significant thermal agitation to annihilate. Irradiation by heavy ions produces damage cascades smaller than that of neutron-induced cascades, and those of proton irradiations are smaller still [53]. However, the damage rate of heavy ion irradiation is higher than neutron irradiation by a factor of $\sim 10^{4}[47,54]$ and proton irradiation damage rates are higher by a factor of $\sim 10^{2}$ [47], accounting for the relative values of $T_{\text {crit }}$ for the Fe-Cr SPP.

While $\mathrm{Zu}$ et al. reported no chemical variation within the Fe-Cr SPPs of Zircaloy-4 after proton irradiation at $350{ }^{\circ} \mathrm{C}$ up to a dose of 7 dpa [47], Fe depletion from such particles is evident in the present work under almost identical irradiation conditions and is shown as a function of dose in Figure 6. As such, we conclude that amorphisation is not a necessary requirement for Fe-depletion under the conditions presented here. In order to elucidate the mechanism(s) involved in amorphisation and/or dissolution, one must calculate the diffusion coefficients of the contributing species in the defective SPP state 
though simulation, which is beyond the scope of the present work, and, indeed, is only beginning to be addressed in the community [55-57]. We may, however, consider the spatial distribution of chemistry as a function of dose. The histogram presented in Figure 6a demonstrates the bimodal distribution of $\mathrm{Fe} / \mathrm{Cr}$ ratios at 4.7 and $7.0 \mathrm{dpa}$. Interestingly, the two $\mathrm{Fe} / \mathrm{Cr}$ modal values do not change significantly between 4.7 and $7.0 \mathrm{dpa}$, suggesting an equilibrium $\mathrm{Fe} / \mathrm{Cr}$ ratio in the edge region that is suitable for the temperature and which may prevent the amorphous transformation from occurring. In Figure 6b, the Fe/Ni histograms again show little difference in the ratio between 4.7 and 7.0 dpa. At $2.3 \mathrm{dpa}$, the very edge of the $\mathrm{Fe} / \mathrm{Ni}$ SPPs seems to have greater $\mathrm{Ni}$ depletion relative to $\mathrm{Fe}$, resulting in a slight skew to the right for the histograms of Figure 6b. This is unexpected as the diffusivity of $\mathrm{Fe}$ is slightly greater than that of $\mathrm{Ni}$ in $\alpha-\mathrm{Zr}$ [37]. However, at higher irradiation doses 4.7 and $7.0 \mathrm{dpa}$, the $\mathrm{Fe} / \mathrm{Ni}$ at the periphery approaches unity, supporting the similar matrix diffusivities of $\mathrm{Fe}$ and $\mathrm{Ni}$ and suggesting that their diffusivity within the $\mathrm{Fe}-\mathrm{Ni}$ SPP is not the same as that in $\alpha-\mathrm{Zr}$. As the $\mathrm{Fe} / \mathrm{Ni}$ largely decreases towards the SPP edge with increasing dose, we believe that the solute is being dispersed into the matrix. While $\mathrm{Zu}$ et al. did not demonstrate chemical evolution within SPPs in Zircaloy-4, this could be due to either a better stability because of the higher $\mathrm{Fe} / \mathrm{Cr}$ ratio in Zircaloy-2 Fe-Cr SPPs $[5,6,41,50,58]$ or due to the limitations associated with single-point EDS sampling or line scans. However, the authors presented energy-filtered TEM, which suggested the possibility of post-irradiation Fe segregation to the matrix-SPP interfacial region for an $\mathrm{Fe}-\mathrm{Cr}$ SPP and to that of a small SPP the authors referred to as $\mathrm{ZrFe}_{2}$ [47]. One must be careful with respect to the interpretation of both observations, as the Fe$\mathrm{Cr}$ SPP in question was located at a grain boundary [47] which may act as a solute pathway, and the determination of ' $\mathrm{ZrFe}_{2}$ ' stoichiometry is difficult given the matrix contribution to the signal from such a small SPP and given that zirconium silicides are known to be coated in $\mathrm{Fe}$ and $\mathrm{Ni}$, segregated to their interface with the matrix after neutron irradiation $[59,60]$; impurity elements such as Si may be easily overlooked if unexpected.
The lack in bimodality for the Fe-Ni SPP in Figure 6 suggests that it has better internal diffusion in comparison to the Fe-Cr SPP. While this is supported in the literature by the resistance to amorphisation of $\mathrm{Fe}-\mathrm{Ni}$ SPPs, commonly explained by the relative diffusivities of $\mathrm{Fe}, \mathrm{Ni}$ and $\mathrm{Cr}$ in $\alpha-\mathrm{Zr}$, there is little work published regarding self-diffusion in the defective $\mathrm{Fe}-\mathrm{Cr}$ or $\mathrm{Fe}-\mathrm{Ni}$ structure. Recent calculations have provided the point defect formation energies in the hcp C14 $\mathrm{ZrCr}_{2}$ and the bct $\mathrm{C} 16 \mathrm{Zr}_{2} \mathrm{Ni}$ systems [57,61]. In the $\mathrm{ZrCr}_{2}$ system, the vacancy-type defects are the least energetically favourable and antisite defects, where $\mathrm{Zr}$ substitutes onto a $\mathrm{Cr}$ site $(\mathrm{ZrCr})$ or $\mathrm{Cr}$ onto a $\mathrm{Zr}$ site $(\mathrm{CrZr})$, are more likely [61]. Therefore, a defective state may be made up of more chemical disorder than of vacancies and interstitials. In the $\mathrm{Zr}_{2} \mathrm{Ni}$ system, the vacancy and antisite defects are on average lower in formation energy than in the $\mathrm{ZrCr}_{2}$ system [57]. This may suggest that if both systems had an equal number of such defects then the $\mathrm{Zr}_{2} \mathrm{Ni}$ would be in a lower free energy state. Although this could account for why the Fe-Ni SPPs recover irradiation damage more effectively than the $\mathrm{Fe}-\mathrm{Cr}$, arguments towards free energy are not strictly valid when one considers the dynamic and localised nature of ballistic collision cascades [38]. Interestingly, vacancy migration in the $\mathrm{Zr}_{2} \mathrm{Ni}$ system was determined to be anisotropic with a preference in the [001] direction [57], which will of course have a profound effect on point defect interactions and larger, extended defects and their evolution, especially in regard to SPP clusters containing both $\mathrm{Fe}-\mathrm{Cr}$ and $\mathrm{Fe}-\mathrm{Ni}$ regions. The $\mathrm{Fe}-\mathrm{Ni}$ system does indeed become defective under neutron irradiation, as Kuri et al. have demonstrated by comparing the EXAFS and XANES with and without neutron irradiation in a BWR [62]. The degree of disorder is, however, difficult to discern and although Kuri et al. described a lack in postirradiation long-range order, the spectra show signs of local order that may exceed that of an amorphous system. Of course, verification by TEM would be beneficial, but such fine detail is not always possible to observe in the microscope when stoichiometry is variable and antisite defects probable, even in the non-irradiated state. 
While such a detailed analysis of segregation within SPPs is not provided here for the neutron-irradiated material, due to the higher irradiation doses and correspondingly lower concentration of $\mathrm{Fe}, \mathrm{Cr}$ and $\mathrm{Ni}$ in the transmission direction causing significant noise in quantifications, spectral imaging to extracts maps such as those in Figure 7 may still provide useful information. For instance, the SPP shape is difficult to discern from the BF STEM image but is clear from the $\mathrm{Fe}, \mathrm{Cr}$ and $\mathrm{Ni}$ maps. Interestingly, the Fe-Ni part of the SPP cluster has an unusual shape in comparison to the Fe-Cr part; the former has a more irregular morphology and the latter is predominantly spheroid with irregular peripheries. This trend is also observed in the proton-irradiated material when comparing Figure 4 and Figure 5. Etoh and Shimada et al. have noted the more irregular morphology of dissolving $\mathrm{Fe}-\mathrm{Ni}$ SPPs in comparison to the $\mathrm{Fe}-\mathrm{Cr}$, as have other authors $[9,12,42,63]$. However, the neutron fluence onset of this morphological irregularity has not been reported. In the present work, the irregular shape of the Fe-Ni type SPP is also observed after proton irradiation at 4.7 and 7.0 dpa dose levels, accentuated at the highest proton dose levels by channelling phenomena. As there is no irregularity in the Fe-Ni type SPPs at 2.3 dpa (see Figure 5), it may be the case that there is a delay in the dissolution of the $\mathrm{Fe}-\mathrm{Ni}$ intermetallic phases to between 2.3 and $4.7 \mathrm{dpa}$. Huang et al. have noted that the $\mathrm{Fe} / \mathrm{Ni}$ ratio remains constant for longer than the $\mathrm{Fe} / \mathrm{Cr}$ in the early stages of neutron irradiation at $\sim 290{ }^{\circ} \mathrm{C}$, which means that either the $\mathrm{Fe}-\mathrm{Ni}$ SPP resists dissolution for longer or that $\mathrm{Fe}$ and $\mathrm{Ni}$ are dissolving at the same rate [49]. An assessment of SPP morphology may allude as to which.

Evidence toward the mechanism for dissolution of SPPs may be deduced from Figure 7 and Figure 8, in the directional segregation of $\mathrm{Fe}$, $\mathrm{Cr}$, and to some extent of $\mathrm{Ni}$, to the trace of the basal plane (horizontal). The segregation is coincident with dislocation positions, which has been shown for $\mathrm{Fe}$ and $\mathrm{Cr}$ segregation in the vicinity of $\mathrm{Fe}-\mathrm{Cr}$ type SPPs at similar distances from the SPPs to those presented here $[12,64]$. Recent calculations have shown that $\mathrm{Fe}, \mathrm{Cr}$ and $\mathrm{Ni}$ diffusion is anisotropic with a preference in the $\langle 0001\rangle$ direction [65], the diffusion of $\mathrm{Zr}$ self interstitials (SIAs) is anisotropic with preferable diffusion in the basal plane and the diffusion of vacancies is only weakly anisotropic [14,66]. As such, the segregation of $\mathrm{Fe}, \mathrm{Cr}$ and $\mathrm{Ni}$ to basal planes in Figure 7 and Figure 8 cannot be a result of their individual diffusion anisotropy but is likely due to the diffusion of SIAs in the basal plane toward SPPs and the resulting back diffusion of alloying elements in the reverse direction. The role of SPPs as sinks for SIAs has been discussed previously [43] and is supported by a lack in SPP dissolution in the neutron irradiation of $20 \%$ cold worked Zircaloy-2 [40]. This behaviour was attributed to network dislocations hindering outward diffusion, but it may be more likely that the network dislocations become the dominant sink for SIAs and SIA clusters, which would serve as indirect evidence for SPPs as SIA sinks in fully recrystallised systems. Further, the close anti-correlation of $\mathrm{Zr}$ with that of $\mathrm{Fe}, \mathrm{Cr}$ and $\mathrm{Ni}$ in Figure 7 may be evidence of Zr SIAs preferentially dissolving the SPP; the fact that Sn does not follow this same anti-correlation indicates that the SPP dissolution is not simply a result of ballistic mixing.

\subsubsection{Chemical quantification}

The average $\mathrm{Fe} / \mathrm{X}(\mathrm{X}=\mathrm{Cr}, \mathrm{Ni})$ ratio over the whole SPP displayed in Figure 9 gives an idea of the scatter in measurement; the mean and standard deviations are given in Table 1. Both the proton- and neutron-irradiated $\mathrm{Fe} / \mathrm{Cr}$ data presented in Figure 9a fit well with data in the literature and describe a decrease in the average $\mathrm{Fe} / \mathrm{Cr}$ with respect to dose. This is expected from the depletion of $\mathrm{Fe}$ from SPP edge regions, exemplified in Figure 4. In Figure 9b, the $\mathrm{Fe} / \mathrm{Ni}$ ratio is displayed in a similar manner. The protonirradiated data fits reasonably well with that in the literature and displays a retention of the mean $\mathrm{Fe} / \mathrm{Ni}$ ratio between 0 and $2.3 \mathrm{dpa}$, agreeing with the observation of Etoh and Shimada that $\mathrm{Fe} / \mathrm{Ni}$ remains constant for longer than $\mathrm{Fe} / \mathrm{Cr}$ at low dose neutron irradiation [42]. This supports the SPP morphology evolution in Figure 5 that suggests a resistance to irradiation-induced dissolution within the Fe-Ni SPP until between 2.3 and 4.7 dpa. The trend between the $\mathrm{Fe} / \mathrm{Ni}$ for the proton and neutron-irradiated material presented here is not, however, as continuous as for the $\mathrm{Fe} / \mathrm{Cr}$. The 
reader is reminded that the non- and protonirradiated material was Zircaloy-2 plate and the neutron-irradiated cladding or channel material. As such, the $\mathrm{Fe} / \mathrm{X}$ ratios of SPPs in the starting material may be different. This potential difference in chemistry is possibly more significant for Fe-Ni than for Fe-Cr SPPs, as Yang has reported that aging of Zircaloy-2 in the high $\alpha$-phase temperature range caused an increase in the $\mathrm{Fe} / \mathrm{Ni}$ of $\mathrm{Fe}-\mathrm{Ni} \mathrm{SPPs}$ from 0.9 to $\sim 1.1$, but did not cause any change in the $\mathrm{Fe} / \mathrm{Cr}$ ratio of the $\mathrm{Fe}-$ $\mathrm{Cr}$ phase [6]. This observation suggests a higher degree of flexibility in the $\mathrm{Fe} / \mathrm{X}$ stoichiometry of the Fe-Ni type than the Fe-Cr type SPP. It should be noted that similar neutron-irradiated material was recently studied in regard to SPP chemistry by Valizadeh et al. [12] and the results from the present work are in good agreement. As such, a wider stoichiometric range of Fe-Ni SPPs may be of significance both before and after neutron irradiation. Indeed, the range given by Valizadeh for the non-irradiated state is larger for the $\mathrm{Fe}-\mathrm{Ni}$ system $(\mathrm{Fe} / \mathrm{Ni}=1.6-2.1)$ than for the $\mathrm{Fe}-\mathrm{Cr}(\mathrm{Fe} / \mathrm{Cr}$ $=0.7-1.1)$ and larger than the $\mathrm{Fe} / \mathrm{Ni}$ range for the non-irradiated plate presented here. The mean $\mathrm{Fe} / \mathrm{Ni}$ at the highest proton dose is similar to the $\mathrm{Fe} / \mathrm{Ni}$ at the highest neutron dose, which may suggest that a stable $\mathrm{Fe} / \mathrm{Ni}$ is eventually reached under both irradiative species at $\mathrm{Fe} / \mathrm{Ni} \sim 0.7$.

In comparing the composition of SPP cores and edges towards the interface, it should be noted that electropolishing can result in preferential dissolution of precipitate/matrix interfaces as the difference in internal potential between the two phases can cause one to be anodic with respect to another [67]. However, such an artefact should not affect $\mathrm{Fe} / \mathrm{X}$ ratios $(\mathrm{X}=$ $\mathrm{Cr}, \mathrm{Ni}$ ) and any effect will likely be the same in the irradiated and non-irradiated conditions. In an analysis of the chemical composition of the $\mathrm{Fe}-\mathrm{Cr}$ SPP Fe-depleted edge region with respect to its core, Figure 10a suggests that the greatest change in Fe-depletion occurs between 2.3 and 4.7 dpa, after which there is little change in the relative chemistry between the two regions. Further, in an analysis of the size of the Fe-Cr SPP Fe-depleted edge region with respect to its core, Figure $10 \mathrm{~b}$ suggests that the greatest increase in edge size occurs between 4.7 and $7.0 \mathrm{dpa}$, before which there is relatively little increase in edge size.
Figure 10 suggests that the degree of Fe-depletion is directly proportional to the surface area of the SPP and hence there is preferential dissolution from the edge. As the SPP volume : surface area ratio decreases with increasing SPP size, Fedepletion from the core must be limited. This is reflected in the mean $\mathrm{Fe} / \mathrm{Cr}$ values for the core and edge regions with respect to dose in Table 2. An analogy from the literature is that of the $\mathrm{Fe}$ depleted amorphous rim in neutron-irradiated FeCr SPPs irradiated at $\sim 300{ }^{\circ} \mathrm{C}$, which is known to ingress towards the crystalline core $[40,43,44]$. However, the rate of amorphous rim ingress in neutron-irradiated material is reported to be linear and independent of SPP size. As a linear rate of ingress of the edge region was not observed in the present work, it may be the case that a stable and equilibrium chemistry is first formed by $\mathrm{Fe}$ depletion in the edge region between 2.3 and 4.7 dpa, after which this equilibrium defective region may ingress towards the central SPP core at a faster rate. The reason for an acceleration in edge ingress rate may be due to either reaching an equilibrium $\mathrm{Fe} / \mathrm{Cr}$ ratio or due to the nucleation of c-loops in the matrix after $\sim 4.5$ dpa proton irradiation at $350{ }^{\circ} \mathrm{C}[68]$, which may act as a strong $\mathrm{Fe}$ sink. The large decrease in $\mathrm{Fe} / \mathrm{Cr}$ between 2.3 and 4.7 dpa could result in matrix segregation that creates c-loop nucleation sites, as could the large decrease in $\mathrm{Fe} / \mathrm{Ni}$.

SPP edge and core size effects, coupled with a variable SPP size prior to irradiation, contributes to an explanation of scatter in Figure 9. The average over the whole SPP is displayed in Figure 11 for both the $\mathrm{Fe}-\mathrm{Cr}$ and Fe-Ni SPPs. As has been already mentioned, Fe/Ni stoichiometry is known to be variable prior to irradiation [12] and variable with respect to heat treatment parameters [6]. Further, with reference to Figure $11 \mathrm{c}$ and $\mathrm{d}$, there seems to be a decrease in the $\mathrm{Fe} / \mathrm{Ni}$ stoichiometry with $\mathrm{Fe}-\mathrm{Ni} \mathrm{SPP}$ size that is retained throughout irradiation to $7.0 \mathrm{dpa}$, again suggesting good diffusional capacity within $\mathrm{Fe}-\mathrm{Ni}$ type SPPs. In Figure 11c and d, the gradient of the line of best fit is similar at all dose levels and this slope is also present in the non-irradiated case. Therefore, it may be the case that relationship between Fe-Ni SPP chemistry and size is not an irradiation-induced phenomenon but one pertaining to the thermomechanical history and 
alloy heat treatment prior to irradiation. In the present work and within these final two figures, we demonstrate the better self-diffusion within the defective state of Fe-Ni SPPs in comparison to that in $\mathrm{Fe}-\mathrm{Cr}$ SPPs. This may lend itself in explanation of the SPPs' relative amorphisation behaviour under neutron irradiation.

\section{Conclusions}

The irradiation-induced dissolution of SPPs, $\mathrm{Fe}-\mathrm{Cr}$ and $\mathrm{Fe}-\mathrm{Ni}$ type, has been exemplified in the present work for both proton- and neutronirradiated Zircaloy-2. The development of transmission electron microscopy in its high spatial resolution through aberration-corrected probes and the development of EDS detectors of large total solid angles, have been essential in obtaining such measurements. The following is a summary of the main conclusions:

- $\mathrm{Fe}-\mathrm{Cr}$ SPPs are heterogeneous before irradiation and contain $\mathrm{Ni}$, whereas $\mathrm{Fe}-\mathrm{Ni}$ SPPs are homogeneous and contain no $\mathrm{Cr}$.

- Neutron irradiation results in Fe-depletion from both $\mathrm{Fe}-\mathrm{Cr}$ and $\mathrm{Fe}-\mathrm{Ni} \mathrm{SPPs}$, the former incurs an amorphous transformation and the latter remains crystalline.

- Proton irradiation at $350{ }^{\circ} \mathrm{C}$ resulted in no amorphisation for either the $\mathrm{Fe}-\mathrm{Cr}$ or $\mathrm{Fe}$ Ni SPPs.

- Proton irradiation results in a core-edge structure for Fe-Cr SPPs. The edge region is Fe-depleted with a composition and size directly proportional to that of the nonirradiated SPP.

- Proton irradiation results in Fe-depletion from the whole of Fe-Ni SPPs, suggesting better self-diffusion in the defective phase in comparison to the Fe-Cr SPP. Larger SPPs have lower Fe contents, likely due to pre-irradiation thermomechanical heat treatment parameters.

- Under both proton and neutron irradiation, $\mathrm{Fe}-\mathrm{Ni}$ SPPs evolve to irregular morphologies whereas $\mathrm{Fe}-\mathrm{Cr}$ SPPs remain spheroid, albeit with irregular edges. The delay in the Fe-Ni morphological change and the delay in the decrease in the average $\mathrm{Fe} / \mathrm{Ni}$ ratio is evidence of better irradiation resistance in comparison to the $\mathrm{Fe}-\mathrm{Cr}$ SPP.

Preliminary work by the present authors in grain boundary chemistry shows a depletion of Fe and $\mathrm{Ni}$ and the segregation of $\mathrm{Sn}$ to all boundaries after irradiation by protons and neutrons. As such, a supersaturation of the matrix with solute is indirectly evident and irradiation-induced precipitation or clustering, either during irradiation or upon cooling, is expected. This has been observed in the present work close to partially dissolved SPPs in neutron-irradiated Zircaloy-2 and an assessment of solute segregation and its interaction with other defect structures is underway. The diffusivity and selfsolubility of $\mathrm{Fe}, \mathrm{Cr}$ and $\mathrm{Ni}$ within the defective SPP structures are scarcely-studied but likely mechanisms by which different SPPs respond differently to both proton and neutron irradiation, as is the initial heterogeneity in the $\mathrm{Fe}-\mathrm{Cr}$ type SPP and its increase in heterogeneity during irradiation.

\section{Acknowledgements}

This work is funded by an EPSRC Leadership Fellowship for the study of irradiation damage in zirconium alloys [EP/I005420/1], with additional industrial contributions especially from Westinghouse and Studsvik Nuclear in terms of both material acquisition and useful discussions. The authors would like to thank Malcolm Griffiths for insightful discussions, Maria Yankova for advice in data analysis, Thomas Seymour for aid in experimental accomplishments and Gary Was and Ovidiu Toader at the Michigan Ion Beam Laboratory for the use of their facility in the proton irradiation experiments.

\section{References}

[1] L. Hallstadius, S. Johnson, E. Lahoda, Cladding for high performance fuel, Prog. Nucl. Energy. 57 (2012) 71-76.

[2] M.M. Stupel, M. Bamberger, B.Z. WEiss, Determination of Fe solubility in $\alpha \mathrm{Zr}$ by Mössbauer spectroscopy, Scr. Metall. 19 (1985) 739-740.

[3] D. Charquet, R. Hahn, E. Ortlieb, J. Gros, J. Wadier, 
Solubility limits and formation of intermetallic precipitates in ZrSnFeCr alloys, Zircon. Nucl. Ind. Eighth Int. Symp. (1988) 405-422.

[4] H. Zou, G.M. Hood, H. Nakajima, J. a. Roy, R.J. Schultz, The solid solubility of Ni and Co in $\alpha-Z r$ : a secondary ion mass spectrometry study, J. Nucl. Mater. 223 (1995) 186-188.

[5] R. Kuwae, K. Sato, E. Higashinakagawa, J. Kawashima, S. Nakamura, Mechanism of Zircaloy nodular corrosion, J. Nucl. Mater. 119 (1983) 229-239.

[6] W.J.S. Yang, R.P. Tucker, R.B. Adamson, Precipitates in Zircaloy: Identification and the Effects of Irradiation and Thermal Treatment, J. Nucl. Mater. 138 (1986) 185-195.

[7] M. Griffiths, R.W. Gilbert, V. Fidleris, R.P. Tucker, R.B. Adamson, Neutron damage in zirconium alloys irradiated at 644 to $710 \mathrm{~K}$, J. Nucl. Mater. 150 (1987) 159-168.

[8] H. Zou, G.M. Hood, J. a. Roy, R.H. Packwood, V. Weatherall, Solute distribution in annealed Zircaloy-2 and Zr-2.5Nb, J. Nucl. Mater. 208 (1994) 159-165.

[9] W. Goll, I. Ray, The Behavior of Intermetallic Precipitates in Highly Irradiated BWR LTP Cladding, Zircon. Nucl. Ind. Thirteen. Int. Symp. ASTM STP 1423. (2002) 80-95.

[10] X. Meng, D. Northwood, Second phases in Zircaloy-2, J. Nucl. Mater. 168 (1989) 125-136.

[11] F. Garzarolli, R. Schumann, E. Steinberg, Corrosion optimized Zircaloy for boiling water reactor (BWR) fuel elements, Zircon. Nucl. Ind. Tenth Int. Symp. ASTM STP 1245. (1994) 709723.

[12] S. Valizadeh, G. Ledergerber, S. Abolhassan, D. Jädernäs, M. Dahlbäck, E. V. Mader, G. Zhou, J. Wright, L. Hallstadius, Effects of Secondary Phase Particle Dissolution on the In-Reactor Performance of BWR Cladding, J. ASTM Int. 8 (2014) 729-753.

[13] S.N. Buckley, Properties of Reactor Materials and the Effects of Irradiation Damage, in: Butterworths, London, 1961: p. 443.

[14] C.H. Woo, U. Göslel, Dislocation bias in an anisotropic diffusive medium and irradiation growth, J. Nucl. Mater. 119 (1983) 219-228.

[15] C.H. Woo, Effects of Anisotropic Diffusion on Irradiation Deformation, in: Radiation-Induced Chang. Microstructre 13th Int. Symp. (PART I), ASTM STP 955, 1987: pp. 70-89.

[16] C.H. Woo, Theory of irradiation deformation in non-cubic metals: effects of anisotropic diffusion, J. Nucl. Mater. 159 (1988) 237-256.

[17] R.A. Holt, Mechanisms of irradiation growth of alpha-zirconium alloys, J. Nucl. Mater. 159 (1988) 310-338.

[18] R.H. Zee, A. Rogerson, G.J.C. Carpenter, J. Watters, Effect of tin on the irradiation growth of polycrystalline zirconium, J. Nucl. Mater. 120 (1984) 223-229.

[19] R. a. Holt, R.W. Gilbert, c-component dislocations in annealed Zircaloy irradiated at about $570 \mathrm{~K}$, J. Nucl. Mater. 137 (1986) 185-189.

[20] M. Griffiths, R.W. Gilbert, V. Fidleris, Accelerated irradiation growth of zirconium alloys, Zircon. Nucl. Ind. Eighth Int. Symp. (1989) 658-677.

[21] A. Jostsons, R.G. Blake, J.G. Napier, P.M. Kelly, K. Farrell, Faulted loops in neutron-irradiated zirconium, J. Nucl. Mater. 68 (1977) 267-276.

[22] M. Griffiths, A review of microstructure evolution in zirconium alloys during irradiation, J. Nucl. Mater. 159 (1988) 190-218.

[23] M. Griffiths, R.W. Gilbert, The Formation of ccomponent defects in zirconium alloys during neutron irradiation, J. Nucl. Mater. 150 (1987) 169-181.

[24] L. Tournadre, F. Onimus, J.-L. Béchade, D. Gilbon, J.-M. Cloué, J.-P. Mardon, X. Feaugas, O. Toader, C. Bachelet, Experimental study of the nucleation and growth of c-component loops under charged particle irradiations of recrystallized Zircaloy-4, J. Nucl. Mater. 425 (2012) 76-82.

[25] Y. de Carlan, C. Regnard, M. Griffiths, D. Gilbon, C. Lemaignan, Influence of Iron in the Nucleation of $<c>$ Component Dislocation Loops in Irradiated Zircaloy-4, Zircon. Nucl. Ind. Elev. Int. Symp. ASTM STP 1295. (1996) 638-653.

[26] R.E. Stoller, M.B. Toloczko, G.S. Was, A.G. Certain, S. Dwaraknath, F. a. Garner, On the use of SRIM for computing radiation damage exposure, Nucl. Instruments Methods Phys. Res. B. 310 (2013) 75-80.

[27] C.R.F. Azevedo, Selection of fuel cladding material for nuclear fission reactors, Eng. Fail. Anal. 18 (2011) 1943-1962.

[28] V.N. Shishov, M.M. Peregud, A. V Nikulina, G.P. Kobylyansky, Z.E. Ostrovsky, Influence of structure-phase state of $\mathrm{Nb}$ containing $\mathrm{Zr}$ alloys on irradiation-induced growth, Zircon. Nucl. Ind. 14th Symp. 2 (2005) 666-685.

[29] M. Griffiths, J.F. Mecke, J.E. Winegar, Evolution of Microstructure in Zirconium Alloys During 
Irradiation, Zircon. Nucl. Ind. Elev. Int. Symp. ASTM STP 1295. (1996) 580-602.

[30] R. Adamson, Charged particle bombardment of zirconium alloys: A review, Sweden, 2014.

[31] G.S. Was, Fundamentals of Radiation Materials Science, in: Fundam. Radiat. Mater. Sci., Springer Berlin Heidelberg New York, 2007: p. 83.

[32] V. Perovic, A. Perovic, G.C. Weatherly, L.M. Brown, G.R. Purdy, R.G. Fleck, R.A. Holt, Microstructural and microchemical of $\mathrm{Zr}-2 \mathrm{SNb}$ pressure tube alloy studies, J. Nucl. Mater. 205 (1993) 251-257.

[33] E.M. Francis, A. Harte, P. Frankel, S.J. Haigh, D. Jädernäs, J. Romero, L. Hallstadius, M. Preuss, Iron redistribution in a zirconium alloy after neutron and proton irradiation studied by energy-dispersive X-ray spectroscopy (EDX) using an aberration-corrected (scanning) transmission electron microscope, J. Nucl. Mater. 454 (2014) 387-397.

[34] D.B. Williams, C.B. Carter, Transmission Electron Microscopy: A Textbook for Materials Science, 2nd ed., Springer Science+Business Media, LLC, 223 Spring Street, New York, NY, 10013, USA, 2009.

[35] B.V. Cockeram, K.J. Leonard, L.L. Snead, M.K. Miller, The use of a laser-assisted Local Electrode Atom Probe and TEM to examine the microstructure of Zircaloy and precipitate structure following low dose neutron irradiation at nominally $358^{\circ} \mathrm{C}$, J. Nucl. Mater. 433 (2013) 460-478.

[36] P. Chemelle, D.B. Knorr, J.B. Van der Sande, R.M. Pelloux, Morphology and composition of second phase particles in Zircaloy-2, J. Nucl. Mater. 113 (1983) 58-64.

[37] R.A. Perez, H. Nakajima, F. Dyment, Diffusion in alpha-Ti and Zr, Mater. Trans. 44 (2003) 2-13.

[38] A.T. Motta, Amorphization of intermetallic compounds under irradiation - A review, J. Nucl. Mater. 244 (1997) 227-250.

[39] J.L. Brimhall, H.E. Kissinger, L. a. Charlot, Amorphous phase formation in irradiated intermetallic compounds, Radiat. Eff. 77 (1983) 273-293.

[40] M. Griffiths, R.W. Gilbert, G.J.C. Carpenter, Phase instability, decomposition and resdistribution of intermetallic precipitates in Zircaloy-2 and -4 during neutron irradiation, J. Nucl. Mater. 150 (1987) 53-66.

[41] R.W. Gilbert, M. Griffiths, G.J.C. Carpenter, Amorphous intermetallics in neutron irradiated Zircaloys after hIgh fluences, J. Nucl. Mater. 135
(1985) 265-268.

[42] Y. Etoh, S. Shimada, Neutron irradiation effects on intermetallic precipitates in Zircaloy as a function of fluence, J. Nucl. Mater. 200 (1993) 59-69.

[43] M. Griffiths, Comments on precipitate stability in neutron-irradiated Zircaloy-4, J. Nucl. Mater. 170 (1990) 294-300.

[44] D. Gilbon, C. Simonot, Effect of Irradiation on the Microstructure of Zircaloy-4, Zircon. Nucl. Ind. Tenth Int. Symp. ASTM STP 1245. (1994) 521548.

[45] R. Bajaj, B.F. Kammenzind, D.M. Farkas, Effects of Neutron Irradiation on the Microstructure of Alpha-Annealed Zircaloy-4, Zircon. Nucl. Ind. Thirteen. Int. Symp. ASTM STP 1423. (2002) 400406.

[46] W.J.S. Yang, Precipitate stability in neutronirradiated Zircaloy-4, J. Nucl. Mater. 158 (1988) 71-80.

[47] X.T. Zu, K. Sun, M. Atzmon, L.M. Wang, L.P. You, F.R. Wan, J.T. Busby, G.S. Was, R.B. Adamson, Effect of proton and Ne irradiation on the microstructure of Zircaloy 4, Philos. Mag. 85 (2005) 649-659.

[48] A.T. Motta, F. Lefebvre, C. Lemaignan, Amorphization of Precipitates in Zircaloy under Neutron and Charged-Particle Irradiation, Zircon. Nucl. Ind. Ninth Int. Symp. ASTM STP 1132. (1991) 718-739.

[49] P.Y. Huang, S.T. Mahmood, R.B. Adamson, Effects of thermomechanical processing on in-reactor corrosion and post-irradiation mechanical properties of Zircaloy-2, Zircon. Nucl. Ind. Elev. Int. Symp. ASTM STP 1295. (1996) 726-757.

[50] D. Pêcheur, F. Lefebvre, A.T. Motta, C. Lemaignan, D. Charquet, Effect of irradiation on the precipitate stability in Zr alloys, J. Nucl. Mater. 205 (1993) 445-451.

[51] A.T. Motta, L.M. Howe, P.R. Okamoto, Amorphization Kinetics of $\mathrm{Zr}(\mathrm{Fe}, \mathrm{Cr}) 2$ under ion irradiation, 1994.

[52] C.H. Woo, B.N. Singh, Production bias due to clustering of point defects in irradiation-induced cascades, Philos. Mag. A. 65 (1992) 889-912.

[53] G.S. Was, The damage cascade, in: Fundam. Radiat. Mater. Sci., Springer Berlin Heidelberg New York, 2000: pp. 125-154.

[54] Y. Idrees, Z. Yao, M. a. Kirk, M.R. Daymond, In situ study of defect accumulation in zirconium under heavy ion irradiation, J. Nucl. Mater. 433 (2013) 95-107. 
[55] P. a Burr, M.R. Wenman, B. Gault, M.P. Moody, M. Ivermark, M. Preuss, L. Edwards, R.W. Grimes, From solid solution to cluster formation of Fe and

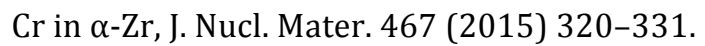

[56] X.-Q. Chen, W. Wolf, R. Podloucky, P. Rogl, M. Marsman, Ab initio study of ground-state properties of the Laves-phase compound ZrMn2, Phys. Rev. B. 72 (2005) 1-11.

[57] C.S. Moura, A.T. Motta, N.Q. Lam, L. Amaral, Point defect energetics in the $\mathrm{ZrNi}$ and $\mathrm{Zr} 2 \mathrm{Ni}$ intermetallics, Nucl. Instruments Methods Phys. Res. B. 175 (2001) 526-531.

[58] J.B. Van der Sande, A.L. Bement, An investigation of second phase particles in Zircaloy-4 alloys, J. Nucl. Mater. 52 (1974) 115-118.

[59] M. Griffiths, C.K. Chow, R.A. Holt, S. Sagat, V.F. Urbanic, Evolution of microstructure in zirconium allo core components of nuclear reactors during service, Ontario K0J 1J0, 1992.

[60] M. Griffiths, Comment on Fe-distribution in zr2.5 Nb pressure tubing, J. Nucl. Mater. 207 (1993) 353-356.

[61] X.-Q. Chen, W. Wolf, R. Podloucky, P. Rogl, Ab initio study of ground-state properties of the Laves phase compounds $\mathrm{TiCr} 2, \mathrm{ZrCr} 2$, and $\mathrm{HfCr} 2$, Phys. Rev. B. 71 (2005) 1-11.

[62] G. Kuri, C. Degueldre, J. Bertsch, S. Abolhassani, Micro-focussed XAFS spectroscopy to study Nibearing precipitates in the metal of corroded Zircaloy-2, Appl. Phys. A Mater. Sci. Process. 98 (2010) 625-633.

[63] S.T. Mahmood, F.D. M, A.R. B, E. Y, PostIrradiation Characterization of ultra-high fluence zircaloy-2, Zircon. Nucl. Ind. Twelfth Int. Symp.
ASTM STP 1354. (2000) 139-169.

[64] M. Griffiths, R.A. Holt, A. Rogerson, Microstructural aspects of accelerated deformation of Zircaloy nuclear reactor components during service, J. Nucl. Mater. 225 (1995) 245-258.

[65] M. Christensen, W. Wolf, C.M. Freeman, E. Wimmer, R.B. Adamson, L. Hallstadius, P.E. Cantonwine, E.V. Mader, Effect of alloying elements on the properties of $\mathrm{Zr}$ and the $\mathrm{Zr}-\mathrm{H}$ system, J. Nucl. Mater. 445 (2014) 241-250.

[66] M. Christensen, W. Wolf, C. Freeman, E. Wimmer, R.B. Adamson, L. Hallstadius, P.E. Cantonwine, E. $V$ Mader, Diffusion of point defects, nucleation of dislocation loops, and effect of hydrogen in hcp$\mathrm{Zr}$ : Ab initio and classical simulations, J. Nucl. Mater. 460 (2015) 82-96.

[67] C. Toffolon-Masclet, J.-C. Brachet, G. Jago, Studies of second phase particles in different zirconium alloys using extractive carbon replica and an electrolytic anodic dissolution procedure, J. Nucl. Mater. 305 (2002) 224-231.

[68] A. Harte, D. Jädernäs, M. Topping, P. Frankel, C. Race, J. Romero, L. Hallstadius, E.C. Darby, M. Preuss, The effect of matrix chemistry on dislocation evolution in an irradiated Zr alloy, Acta Mater. Submitted (2017).

[69] T. Sawabe, T. Sonoda, S. Kitajima, T. Kameyama, Analysis of atomic distribution in as-fabricated Zircaloy-2 claddings by atom probe tomography under high-energy pulsed laser, J. Nucl. Mater. 442 (2013). 